Article

\title{
Physical, Bio-Optical State and Correlations in North-Western European Shelf Seas
}

\section{Shungudzemwoyo P. Garaba *, Daniela Voß and Oliver Zielinski}

Institute for Chemistry and Biology of the Marine Environment-Terramare, Carl von Ossietzky University of Oldenburg, Schleusenstraße 1, D-26382 Wilhelmshaven, Germany;

E-Mails: daniela.voss@uni-oldenburg.de (D.V.); oliver.zielinski@uni-oldenburg.de (O.Z.)

* Author to whom correspondence should be addressed; E-Mail: shungu.garaba @ uni-oldenburg.de; Tel.: +49-4421-944-185; Fax: +49-4421-944-140.

Received: 14 January 2014; in revised form: 21 May 2014 / Accepted: 23 May 2014 /

Published: 30 May 2014

\begin{abstract}
Color of seawater has become an integral tool in understanding surface marine ecosystems and processes. In this paper we seek to assess the correlations and consequently the potential of using shipborne remote sensing products to infer marine environmental parameters. Typical seawater parameters are chlorophyll-a (chl-a), colored dissolved organic material (CDOM), suspended particulate material (SPM), Secchi-disk depth (SDD), temperature, and salinity. These parameters and radiometric quantities were observed from a total of 60 stations covering German Bight, North Sea, Inner Seas, Irish Sea, and Celtic Sea. Bio-optical models developed in this study were used to predict the in situ measured parameters, with low mean unbiased percent differences and absolute percent difference less than $35 \%$. Our investigations show that the use of ocean color products namely the Forel-Ule Index to infer seawater parameters is encouraging. The constrained spatial and temporal span of measured in situ parameters does limit the accuracy of our models. Absorption coefficients of the main color producing agents CDOM, chl- $a$, and inorganic fraction of SPM (iSPM) were determined to estimate absorption budgets. During the field campaign, iSPM was the primary light absorber over the spectral range (400-700 nm) although variabilities were observed in the regional seas.
\end{abstract}

Keywords: ocean color; bio-optical modeling; marine environmental parameters 


\section{Introduction}

Optically active seawater constituents interact with sunlight depending on their inherent optical properties (IOPs), i.e., ability to absorb, attenuate, re-emit, reflect, or scatter light. Typical optically active seawater constituents responsible for color of seawater are colored dissolved organic matter (CDOM), chlorophyll-a (chl-a) a common pigment in phytoplankton, and suspended particulate material (SPM). These seawater constituents are also known as color producing agents (CPAs). As CPAs are optically active seawater constituents their IOPs can be correlated to or influenced by seawater physical properties, such as salinity, temperature, and water transparency [1-3].

CDOM, also known as Gelbstoff, gilvin, or yellow substance is the optically active fraction of dissolved organic material $(<0.2 \mu \mathrm{m})$ in seawater, which originates from plant and animal decay either from terrestrial or marine environments [2,4]. Its light absorption coefficient decays almost exponentially, from high absorption coefficients in the ultra-violet to close to zero towards red spectral range $[5,6]$. A strong near-linear negative correlation between CDOM absorption and salinity has been observed in most shelf sea studies [7,8]. This correlation has been pivotal in studies aimed at improving remote sensing of CDOM and salinity in shallow waters [4,9]. In open seas as CDOM is commonly found at low concentrations measurements are challenging. Despite the accuracy there is a growing number of CDOM estimation algorithms using a key ocean color product-remote sensing reflectance $\left(R_{R S}\right)$ that have been reviewed recently [10].

$\mathrm{Chl}-a$ is a classic proxy of ocean phytoplankton biomass. It is the most common pigment in living plants that absorbs blue-red light $[11,12]$. In coastal and shelf seas, chl- $a$ estimation from bio-optical models and its influence on color of seawater is affected by the overlap and decoupling of absorption resulting from other CPAs namely CDOM and non-algal components of SPM [13,14]. Chl-a as a principal CPA will give seawater a bluish to greenish color. However, there are some cases were different colors have been observed in waters highly concentrated with chl- $a$. For instance during harmful cyanobacteria blooms seawater can be milky blue or from densely localized phytoplankton have a reddish color [15,16]. Although these colors of seawater are attributed to CPAs, Dierssen et al. [15] ran some Hydrolight (Sequoia Scientific Inc., Seattle, WA, USA) simulations which suggest that color of seawater also depends on the observer's eye color perception.

Typically SPM consists of re-suspended sediments, particulate organic matter, plankton, and detritus [17,18]. The inorganic fraction of SPM (iSPM) is another optically significant seawater constituent influencing the color of seawater [9]. In ocean, color mineral solids are the remaining inorganic material after combustion; these are considered to be a CPA. The color of seawater driven by high SPM concentrations produces mostly reddish to brown waters although different shades can result from varying mineral compositions [15,19]. Measuring SPM is not challenging but accuracy, as well as precision of measurements varies depending on skills, instrumentation and approach implemented and therefore turbidity can also be used to assess the type of SPM [20,21]. Water turbidity is a proxy for transparency or scattering material and is driven by the amount of scattering suspended material at a location, the particulate material physical properties and medium refractive index. Hence, the backscattered light is dependent on the physical characteristics of the SPM [22]. For instance, if SPM in high concentrations is strongly absorbing the observed turbidity will be relatively low. Otherwise, turbidity will be high if the SPM in high concentrations is strongly scattering. 
The typical classification of water bodies is based on the concentration of dissolved and particulate material and water transparency [23-25]. Taking advantage of the long record of Forel-Ule ocean color observations, we implement a recent objective colorimetric calculation system [26] to transform hyperspectral radiometric reflectance into discrete Forel-Ule Indices. The use of RGB cameras is not well established but gaining interest for sea Forel-Ule observations or CPAs [27]. The main challenges are; (i) focusing the camera to target water body; (ii) eliminating over-exposure effects from surface reflected glint in case it is set up on big ship above-water; (iii) calibrating the image to local region natural colors; and (iv) matching images to radiometric quantities for validation tasks [28]. Available hyperspectral radiometers offer stable and durable all weather optical sensors capable of collecting radiometric quantities used to derive ocean color products, e.g., the Forel-Ule Index, reflectance, and infer CPAs [16,29].

The framework of this study was to explore and assess the extent of correlations among environmental parameters, like CDOM, turbidity, chl-a, temperature, salinity, Secchi-disk depth (SDD), iSPM, $R_{R S}$ derived Forel-Ule Indices in northwest European shelf seas. We also investigate and present the application of ocean color products in monitoring marine environments using the classic Forel-Ule color scale with the potential to link the new ocean color derived Forel-Ule observations to historical datasets. Furthermore $R_{R S}$ spectra shape and band ratio relationships will be tested to distinguish in situ station into Case 1 or Case 2 waters [24]. Average absorption coefficient budgets for these investigated seas will be explored using a classical approach [25].

\section{Methods}

\subsection{Study Area}

The investigated northwest European shelf seas (NWES) span across the German Bight, North Sea, Inner Seas, Irish Sea, Celtic Sea, and English Channel are shown in Figure 1. Sampling took place between 21 April and 9 May 2009, aboard R/V Heincke cruise HE302. Most of the stations were close to the coast as the main objective of this study was to assess favorable conditions for harmful algal blooms. Therefore strong dynamical changes of the observed parameters were expected. These areas constitute some of the marginal basins of the North Atlantic characterized by elaborate temporal-spatial scale fluctuations [30,31]. Regional fluctuations resulting from strong tidal changes, high freshwater inflow (e.g., Thames and Humber in England, Forth in Scotland, Rhine in Holland, Ems-Dollart, as well as Weser and Elbe in Germany) and Atlantic inflow [31]. It is presumed that perceived color of seawater in the NWES is strongly driven by CDOM and SPM although chl-a plays a seasonal and local role for example in the Central North Sea [32-35]. 
Figure 1. Track of R/V Heincke cruise HE302 in April/May 2009. The red line indicates underway hyperspectral optical measurements (15 min intervals). In situ station (blue dots) sampling was done in the German Bight (1-8), North Sea (9-26), Inner Seas (27-34), Irish Sea (35-43), and Celtic Sea (44-60). Region naming is based on maps from The Germany Federal Maritime and Hydrographic Agency [34] and International Hydrographic Organization [35].

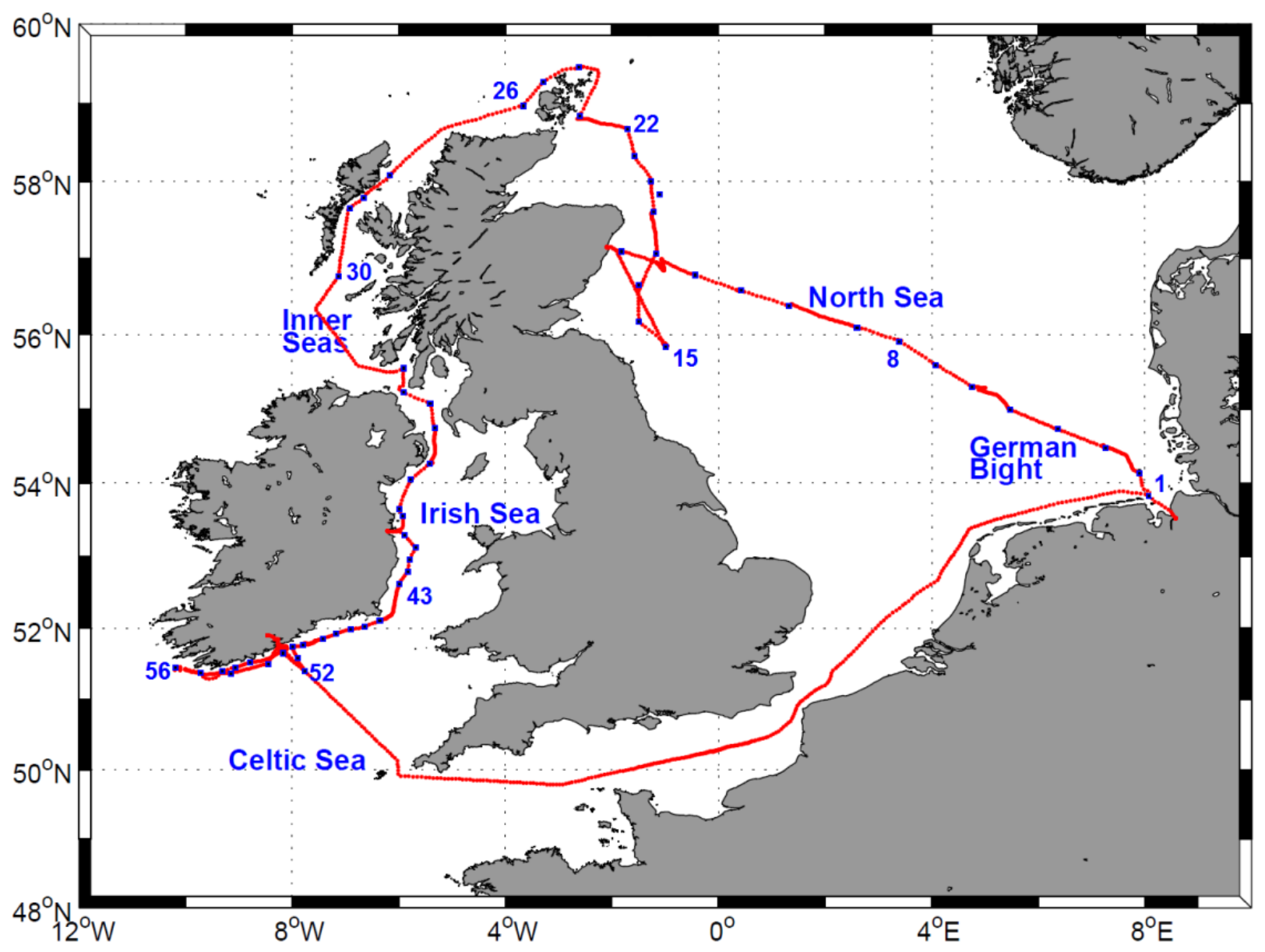

\subsection{Underway Sampling Remote Sensing Reflectance}

Two RAMSES ARC hyperspectral radiance sensors and one RAMSES ACC hyperspectral cosine irradiance sensor (TriOS Mess- und Datentechnik $\mathrm{GmbH}$, Rastede, Germany) were used for continuous above-water radiometric measurements in 15 min intervals. A detailed description of the instrumental setup and quality control of measurements is presented in a previous study [36]. The quality control involved eliminating contaminated measurements, i.e., those taken at dusk and dawn before significant incoming solar radiation could be detected, under rainfall, or with excessive glint as detected by an image algorithm [36]. To compute water leaving radiance $L_{W}\left(\theta_{\text {sfc }}, \Phi, \lambda\right)$ and remote sensing reflectance $R_{R S}(\theta, \Phi, \lambda)$, surface reflected glint correction was implemented according to a recent protocol [37] with the basic Equation (1):

$$
R_{R S}=\frac{L_{W}}{E_{D}}=\frac{L_{T}-L_{S R}}{E_{D}}
$$


where $E_{D}(\lambda)$ is downwelling solar irradiance, $L_{T}\left(\theta_{T}, \Phi, \lambda\right)$ is total upwelling sea surface radiance, and $L_{S R}\left(\theta_{s k y}, \Phi, \lambda\right)$ is the surface reflected glint. Surface reflected glint is a fraction of the sky leaving radiance and some residual glint depending on the surface reflected glint correction approach implemented. The surface reflected glint correction is explained in detail in Garaba and Zielinski [37]. The sky and sea surface radiance sensors were positioned at zenith angle, $\theta_{T}=45^{\circ}$ and $\theta_{\text {sky }}=135^{\circ}$ although these angles were slightly changing due to wave induced roll and pitch of ship. $\Phi$ the relative azimuthal angle of the sensor system to the sun was variable due to ship motions but due to heavily overcast skies the effect of $\Phi$ is assumed negligible as we have diffuse light. Radiometric measurements and computed parameters can be accessed via the PANGAEA database of the World Data Centre for Marine Environmental Sciences [38].

\subsection{Forel-Ule Colorimetric Calculation}

A colorimetric calculation system [26] based on the FUI was implemented. It compresses $R_{R S}$ derived in Equation (1) between (380-720) $\mathrm{nm}$ into a single discrete number. The system transforms spectral information by convolution of 1931 CIE-20-Color Matching Functions and $R_{R S}$. The convolution products are tristimuli values, which are the same as the proportion of the three principal colors: red, green, and blue. The resulting tristimuli values are mapped on a chromaticity diagram matching discrete numerical numbers on a Forel-Ule Scale. Such a method classifies seawater bodies using a discrete numerical index on this scale (see Figure 2), 1 (indigo-blue, oligotrophic) to 21 (cola brown, hyper-eutrophic). A concise explanation of the procedure and history of the Forel-Ule is presented by Wernand [26] and the MATLAB 2013a (The MathWorks GmbH, Ismaning, Germany) code is available on request.

Figure 2. The Forel-Ule Scale and the matching perceivable colors. The RGB values are from Table 6.5 in Wernand [26].

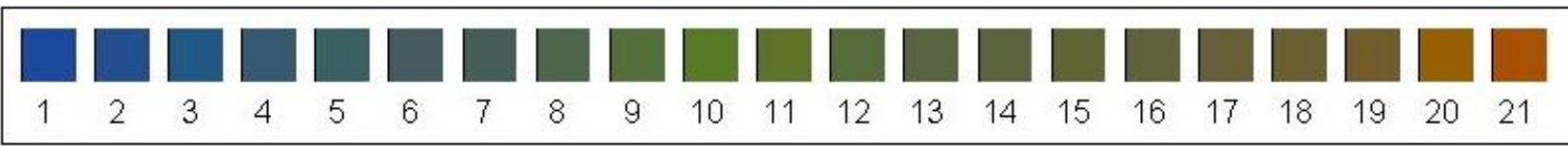

\subsection{Station Sampling}

Station sampling was performed at 60 stations on the NWES cruise track. For standard oceanographic parameters a SBE 19 plus V2 SEACAT CTD (Sea-Bird Electronics Inc., Seattle, WA, USA) with water sampler (SBE 55 ECO) was used. Subsurface seawater samples were taken in 4 L Niskin bottles at $3 \mathrm{~m}$ depth for reference measurements of CDOM, chl- $a$ and SPM. Water transparency was estimated using a $20 \mathrm{~cm}$ diameter white Secchi-disk whilst turbidity was measured with a Seapoint turbidity meter (Seapoint Sensors Inc., Brentwood, NH, USA) attached to the CTD frame. Reference sampling was done in duplicate.

To determine chl $-a$ concentrations sampled seawater $(250-750) \mathrm{mL}$ was filtered under low vacuum through Whatman $\mathrm{GF} / \mathrm{F}^{\mathrm{TM}}$ filters with nominal pore size of $0.7 \mu \mathrm{m}$. The filtration unit was covered to protect samples from light. Until laboratory analysis filters were frozen and stored at $-25^{\circ} \mathrm{C}$. Pigment extraction was done in a $90 \%$ acetone solution, overnight at $4{ }^{\circ} \mathrm{C}$. The extract was centrifuged 
for $10 \mathrm{~min}$ at $3020 \times \mathrm{g}$. Fluorescence of the supernatant was measured with a pre-calibrated TD-700 laboratory fluorometer (Turner Designs, Sunnyvale, CA, USA). Computation of chl- $a$ concentration $(\mu \mathrm{g} / \mathrm{L})$ was done according to EPA Method 446.0 protocol [39].

SPM concentrations were determined gravimetrically. Sampled seawater (250-500) $\mathrm{mL}$ was filtered under low vacuum through dry, pre-combusted and pre-weighed Whatman $G F / F^{\mathrm{TM}}$ filters with nominal pore size of $0.7 \mu \mathrm{m}$. To remove salt, the filters were rinsed with distilled water. Filters were stored at $-25{ }^{\circ} \mathrm{C}$, dried in laboratory at $60{ }^{\circ} \mathrm{C}$ for $\sim 12 \mathrm{~h}$, and reweighed. To determine the inorganic material the filters were combusted at $500{ }^{\circ} \mathrm{C}$ overnight and reweighed. Concentrations were normalized to $1 \mathrm{~L}$.

For CDOM analysis seawater $\sim 200 \mathrm{~mL}$ was filtered under low vacuum through a wet $0.2 \mu \mathrm{m}$ membrane filter (Sartorius AG, Göttingen, Germany). The filtration unit had been pre-rinsed three times with Milli-Q water (Millipore, Billerica, MA, USA), followed by sample water $\sim 100 \mathrm{~mL}$ to avoid contamination with prior samples. Optical density $O D_{C D O M}$ or absorbance of the filtrate was measured onboard in a $0.1 \mathrm{~m}$ quartz cuvette, pre-rinsed three times with filtered sample water, using a UV-VIS-Spectrophotometer double beam UV2450 (Shimadzu, Kyoto, Japan). Samples were scanned in $1 \mathrm{~nm}$ intervals over the range of (200-700) nm. Milli-Q water was used as reference. Additionally retain samples $\left(50 \mathrm{~mL}\right.$, amber bottles) of filtrate were taken and stored at $4{ }^{\circ} \mathrm{C}$ for later laboratory analysis. Absorption coefficients $a_{C D O M}(\lambda)\left(\mathrm{m}^{-1}\right)$ were derived from the $O D_{C D O M}$ measurements using Equation (2)

$$
\mathrm{a}_{C D O M}(\lambda)=\frac{2.3026 \times O D_{C D O M}(\lambda)}{L}
$$

where the factor 2.3026 is derived from the conversion of a base 10 to a natural logarithm and $L$ is the quartz cuvette's pathlength of $0.1 \mathrm{~m}$. A baseline correction was applied using average $O D_{C D O M}$ around (690-700) nm following other studies, e.g., [40,41]. The spectral slope $S_{C D O M}\left(\mathrm{~nm}^{-1}\right)$ was calculated in MATLAB 2013a (The MathWorks GmbH, Ismaning, Germany) from a non-linear least squares exponential fit to $a_{C D O M}$ (Equation (2)) between 350 and $500 \mathrm{~nm}$. Equation (3) [5] was used to calculate $a_{C D O M}$ at any wavelength.

$$
\mathrm{a}_{C D O M}(\lambda)=\mathrm{a}_{C D O M}\left(\lambda_{0}\right) \mathrm{e}^{\left[-S_{C D O M}\left(\lambda-\lambda_{0}\right)\right]}
$$

where reference $a_{C D O M}\left(\lambda_{0}=375 \mathrm{~nm}\right)$. CDOM hereafter refers to $\mathrm{a}_{C D O M}(375)$.

\subsection{Uncertainty and Statistics}

To evaluate the difference between model prediction $X_{\text {prediction }}$ and in-situ observation $X_{\text {in-situ }}$ of any environmental proxy in this study, e.g., $X=$ CDOM, mean absolute percent difference (MAPD) is calculated with Equation (4),

$$
M A P D=100 \% \times \frac{1}{N} \sum_{i=1}^{N} \frac{\left|X_{\text {prediction }}-X_{\text {in-situ }}\right|}{X_{\text {in-situ }}}
$$

where $N$ is the number of in situ measurements for each water body. However, if the accurate value is unknown the unbiased percent difference UPD Equation (5) is calculated. For example at sampling 
time in some cases parameters were measured in duplicate. The threshold for acceptable measurements was set to $25 \%$ to account for sample handling and preparation errors.

$$
U P D=200 \% \times \frac{\left|X_{\text {measurement_1 }}-X_{\text {measurement_2 }}\right|}{X_{\text {measurement_1 }}+X_{\text {measurement_2 }}}
$$

Linear relationships among observed environmental parameters were determined in MATLAB 2013a (The MathWorks GmbH, Ismaning, Germany). In this paper the focus is on assessing the quality of fit $(R)$, statistical significance $F$-statistic ( $p$-value), measure of average uncertainty in model prediction MAPD and UPD as widely presented in literature [8,21,42-44].

\section{Results and Discussion}

\subsection{Variation of CPAs in Northwest European Shelf Seas}

A summary of the in situ measurements collected during the R/V Heincke cruise HE302 is given in Table 1. Appendix Table A1 provides a summary of these measurements as mean \pm standard deviation. Open access to the measurements is available via the PANGAEA database of the World Data Centre for Marine Environmental Sciences: salinity, temperature, turbidity [45], and SDD [46]. For quality control all duplicate measurements with an unbiased percent difference UPD > 25\% were eliminated.

Table 1. Summary of measurements used in this study from the Northwest European shelf seas. Each parameter is presented as minimum-maximum value for $N$ stations observed.

\begin{tabular}{|c|c|c|c|c|c|c|c|c|c|}
\hline Region & $N$ & $\begin{array}{c}\text { CDOM } \\
\left(\mathrm{m}^{-1}\right)\end{array}$ & $\begin{array}{l}\text { Chl-a } \\
(\mu g / L)\end{array}$ & $\begin{array}{l}\text { iSPM } \\
(\mathrm{mg} / \mathrm{L})\end{array}$ & FUI & Salinity (psu) & SDD (m) & $\begin{array}{c}\text { Temperature } \\
\left({ }^{\circ} \mathbf{C}\right)\end{array}$ & $\begin{array}{c}\text { Turbidity } \\
\text { (FTU) }\end{array}$ \\
\hline German Bight & 8 & $0.23-1.71$ & $1.1-19.0$ & $0.16-12.59$ & $3-17$ & $28.13-35.16$ & $2.0-15.2$ & $7.4-11.2$ & $0.06-0.56$ \\
\hline North Sea & 18 & $0.05-0.38$ & $1.1-45.3$ & $0.11-25.79$ & $3-9$ & $34.40-35.14$ & $5.1-12.0$ & $7.4-8.8$ & $0.05-0.85$ \\
\hline Inner Seas & 8 & $0.17-0.43$ & $1.46-13.47$ & $11.64-27.29$ & $4-11$ & $33.73-35.37$ & $5.2-11.6$ & $8.4-10.2$ & $0.08-1.37$ \\
\hline Irish Sea & 9 & $0.31-0.44$ & $1.20-3.56$ & $11.12-25.18$ & $4-9$ & $33.70-34.20$ & $2.2-7.2$ & $9.0-10.3$ & $0.14-1.91$ \\
\hline Celtic Sea & 17 & $0.05-0.48$ & $0.61-3.97$ & $11.92-25.10$ & $4-8$ & $34.23-35.25$ & $5.1-7.9$ & $9.2-10.9$ & $0.16-1.90$ \\
\hline
\end{tabular}

The seawater constituents investigated in this study demonstrated spatial variability (Appendix Figure A1 and Table A1). This diversity was likely a result of rapid changes in seawater especially during bloom/post-bloom collapse phase, in these waters spring bloom have been reported from late February to late May [47,48]. Furthermore, the measured environmental parameters in Table 1 fall within the range of previous investigations in these north-western shelf seas $[9,33,40,42,49]$. These regions are typically fed by some of the major rivers introducing both organic and inorganic material enhancing locally observed concentrations of CDOM and water transparency. CDOM concentrations (Appendix Figure A1 and Table A1) are high in areas close to coast with the highest levels in the German Bight and lowest in the North Sea. In these waters using the observations in (Appendix Table A1) there is an indirect relationship between chl- $a$ and iSPM. In the German Bight high chl- $a$ coincides with low iSPM and high iSPM in the Celtic Sea coincides with low chl-a.

Chl- $a$ concentrations suggest a post-bloom phase with high concentrations near coastal areas and also in the central North Sea. These observations were verified using the European Marine Ecosystem 
Observatory database [50] with chl- $a$ observations ranging between (0-30)/L. It was assumed that during this bloom/post-bloom collapse phase, April/May, more sunlight reached the sea surface but a depleted nutrient supply induces a limited primary production. However, in the shallow waters local chl- $a$ can be influenced by; (i) upwelling of nutrients enhancing biomass production; (ii) freshwater inflow with high biomass; (iii) anthropogenic activities; (iv) dinoflagellates moving up to the surface to photosynthesize or down to harvest nutrients below the salinity stratified waters [12]. We also assume the high concentration in the open ocean could be a result of a localized bloom.

iSPM measurements were correlated with turbidity observations from CTD profiles by linear fitting. The correlation coefficient $R<0.03$ for the German Bight, North Sea, and Celtic Sea, $\sim 0.2$ for the Inner Seas, was relatively low. However, this bad correlation could suggest that the iSPM in most of the regions was strongly absorbing light. In the Irish Sea $R=0.6$ and with statistical significance could suggest the presence of relatively more scattering components in the local iSPM.

Scatter plots and statistics for all measured parameters in northwest European shelf seas are shown in Figure 3. The statistics and plots of each respective water body are presented in the Appendix. Using the $F$-statistic $p$-value some of the relationships show statistical significance despite low correlation coefficient $R$ values.

Figure 3. Statistics (correlation coefficient $r$-squared $R, F$-statistic $p$-value $p$, and number of data points $\mathrm{N}$ ) for the environmental parameters measured in Northwest European Shelf Sea during R/V Heincke cruise HE302 in April/May 2009. The grey lines indicate least square best fit lines and data points are; German Bight (red dots), North Sea (black dots), Inner Seas (blue dots), Irish Sea (green dots), and Celtic Sea (magenta dots).
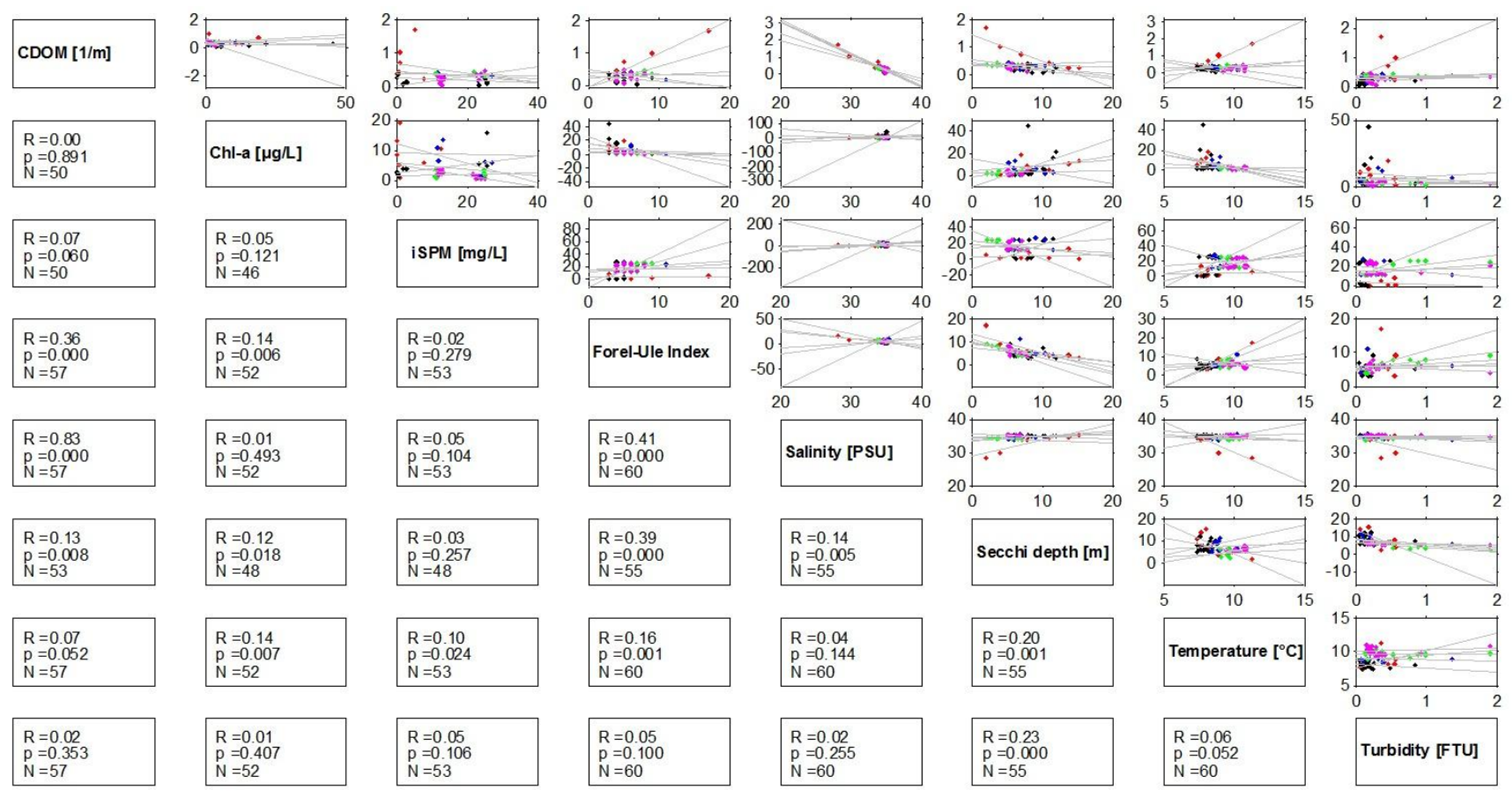

It is clear that this study, like other works in the respective water bodies, is constrained by the available number of measurements and partly by the bloom/post-bloom phase dynamics. The absence of statistical significance, common $(p \leq 0.05)$, which is an arbitrary threshold and is influenced by 
population size, could also suggest that the parameters might exhibit non-linear relationship and therefore need to be explored extensively with more field observations. The measurements were collected during a bloom/post-bloom phase; hence, changes in seawater constituents are very rapidly complicating observations of expected near-theoretical relationships. Figure 3 only assume linear correlations resulting in low $R$ or no statistical significance $(p>0.05)$. However, other correlations might actually exist but show no linearity and should be investigated in future.

\subsection{Colored Dissolved Organic Material (CDOM) and Salinity}

A total of 57 of the 60 stations were matched showing a general strong trend of decreasing CDOM with increasing salinity in all water bodies (Figure 3). As remote sensing of shelf sea and coastal water salinity-using CDOM is gaining interest in ocean color, a set of regional algorithms were determined (Table 2). The correlation coefficient $R$ varied between $(0.16-0.90)$. These algorithms show statistical significance $(p \leq 0.05)$ with exception of the North Sea and Celtic Sea. It could be a result of a limited conservative relationship between $\mathrm{CDOM}$ and salinity. This relationship is strongly influenced by mixing of freshwater (low salinity, high CDOM) and seawater (high salinity, low CDOM). Additionally, it is also assumed that any departure from a linear trend on this figure would be taken to indicate production or consumption of CDOM [4,51]. We therefore assume there is some production or consumption of CDOM in both the North Sea and Celtic Sea leading to the non-linear trend (see Appendix). In the Irish Sea, Inner Seas, and German Bight there is a more pronounced negative correlation between the in-situ CDOM and salinity. To see how the algorithm salinity predictions vary from the in situ measurements MAPDs were determined. Average MAPDs were very low <5\% suggesting some potential in remote sensing of salinity utilizing CDOM. However, the algorithms in Table 2 will be different for each field campaign due to local dynamics influenced by meteorological and seawater conditions, therefore, will need to be tuned.

Table 2. Straight line fit equations for estimating salinity from $a_{C D O M}$ evaluated using $N$ stations to compute correlation coefficient $R$, mean square error $\left[1 / \mathrm{N}(y(i)-x(i))^{2}\right] M S E$, mean absolute percent difference $M A P D$, and $F$-statistic $p$-value.

\begin{tabular}{ccccccc}
\hline Region & Salinity & $\boldsymbol{N}$ & $\boldsymbol{R}$ & $\boldsymbol{M S E}$ & $\boldsymbol{M A P D}$ & $\boldsymbol{p}$-value \\
\hline German Bight & $36.1-4.8 \times a_{C D O M}$ & 8 & 0.90 & 0.81 & $1.90 \pm 1.62$ & $\leq 0.05$ \\
North Sea & $35.0-0.9 \times a_{C D O M}$ & 18 & 0.16 & 0.04 & $0.45 \pm 0.28$ & $>0.05$ \\
Inner Seas & $36.4-6.1 \times a_{C D O M}$ & 8 & 0.69 & 0.11 & $0.55 \pm 0.65$ & $\leq 0.05$ \\
Irish Sea & $35.1-3.1 \times a_{C D O M}$ & 9 & 0.44 & 0.19 & $0.27 \pm 0.25$ & $\leq 0.05$ \\
Celtic Sea & $35.2-1.1 \times a_{C D O M}$ & 14 & 0.22 & 0.06 & $0.58 \pm 0.33$ & $>0.05$ \\
All Seas & $35.8-4.4 \times a_{C D O M}$ & 57 & 0.83 & 0.22 & $1.11 \pm 0.91$ & $\leq 0.05$ \\
\hline
\end{tabular}




\subsection{Ocean Color Product Forel-Ule Index (FUI) and Secchi-Disk Depth (SDD)}

The prospect of obtaining SDD from an ocean color product, e.g., FUI is considered. There is a negative correlation between SDD and FUI shown in Figure 3 and Appendix. It is consistent with the fact that in coastal waters high concentration of CPAs will limit the light penetration depth, hence, low SDD. For example in the German Bight there is low SDD (2 m) and dark waters high FUI (17). Likewise, in the open sea the CPAs, namely iSPM and CDOM, become depleted and, hence, deep light penetrating depths-low FUI (3) and high SDD (15.2 m). The $R$ range $(0.17-0.96)$ and algorithms in Table 3 show statistical significance $(p \leq 0.05)$ with the exception of the North Sea and Inner Seas. Average MAPDs $<60 \%$, offer room for improvement of model sensitivity. As little work has been done to relate SDD to the ocean color product FUI we believe our findings are encouraging.

Table 3. Straight line fit equations for estimating Secchi-disk depth (SDD) from reflectance derived Forel-Ule Index (FUI) is evaluated using $N$ stations to compute correlation coefficient $R$, mean square error $M S E$, mean absolute percent difference $M A P D \pm$ standard deviation, and $F$-statistic $p$-value.

\begin{tabular}{ccccccc}
\hline Region & $\boldsymbol{S D D}$ & $\boldsymbol{N}$ & $\boldsymbol{R}$ & $\boldsymbol{M S E}$ & $\boldsymbol{M A P D}$ & $\boldsymbol{p}$-value \\
\hline German Bight & $13.5-0.8 \times$ FUI & 8 & 0.63 & 8.90 & $35 \pm 24$ & $\leq 0.05$ \\
North Sea & $10.6-0.6 \times$ FUI & 18 & 0.17 & 3.78 & $19 \pm 13$ & $>0.05$ \\
Inner Seas & $10.8-0.5 \times$ FUI & 8 & 0.20 & 5.37 & $27 \pm 11$ & $>0.05$ \\
Irish Sea & $10.7-0.9 \times$ FUI & 8 & 0.96 & 0.16 & $8 \pm 3$ & $\leq 0.05$ \\
Celtic Sea & $8.7-0.5 \times$ FUI & 13 & 0.33 & 0.60 & $11 \pm 6$ & $\leq 0.05$ \\
All Seas & $11.2-0.7 \times$ FUI & 55 & 0.37 & 5.13 & $27 \pm 28$ & $\leq 0.05$ \\
\hline
\end{tabular}

\subsection{Ocean Color Product Forel-Ule Index FUI and Salinity/Temperature}

It has been long established that salinity correlates negatively to CDOM and remote sensing is capable of estimating CDOM [10]. We investigate the possibility of using ocean color product derived here, FUI, to infer salinity presented in Figure 3 and Appendix. To some extent we presume; a salinity increase will coincide with a change in color of coastal seawater, i.e., decreasing FUI also known as bluing offshore; and an increase in FUI high values will result in browning of water nearshore. The results in the North Sea and German Bight do agree with our hypothesis as they are along a transect. Nevertheless, it is evident that linear correlations between salinity or temperature and FUI are not straightforward. We need to consider that FUI is a product of IOPs and the physical properties of seawater. It might not exhibit the checked linear relationship but possibly a non-linear relationship with more parameters. To our knowledge no study has investigated this relationship and there is need to explore other possibilities. Additionally, we have to consider temperature has an optical signature that can be remotely sensed using satellites, e.g., it is a product of Moderate Resolution Imaging Spectroradiometer and Advanced Very High Resolution Radiometer.

\subsection{Color of Seawater}

Up to now there is no prescribed surface reflected glint correction approach [37]. However, we implemented steps introduced in a recent study [44]. The quality control steps were; (a) visual inspection 
of the $R_{R S}$ plots to identify negative spectra over the whole spectrum measured (b) the remaining spectra were then assessed by regression coefficient $R$ for $R_{R S}$ chl-a estimates from the 15 generalized IOP GIOP-algorithm [52] chlorophyll algorithms against in situ observations. The best straight line fit had a regression coefficient $R=0.55$ and with a statistical significance $(p<0.05)$ from 52 matched chl- $a$ measurements with the Coastal Zone Color Scanner CZCS operational chl- $a$ algorithm in GIOP. Based on the above approach, this study used hyperspectral radiometric measurements corrected after surface reflected glint correction R06 explained in a recent protocol [37].

\subsubsection{Using Underway Hyperspectral Radiometric Information}

A total of 487 hyperspectral radiometric measurements collected from and to Bremerhaven were converted into the FUI system. Figure 4 shows all the remote sensing points and their corresponding perceived color based on the FUI scale. The running average for 11 measured points was randomly chosen to show the estimated color of seawater changes. High FUI values are located in the shallow waters or estuary region and in some cases in the open sea. In the open sea these high FUIs suggest either localized rapid changes in CPAs or $R_{R S}$ conversion to FUI was not accurate enough. The fact that $\sim 84 \%$ of measurements were eliminated during quality control makes it a challenge to present a complete map of the color changes during the cruise. Therefore it is difficult to explain why in the open sea areas we also observe high FUI values. Interpolating these FUI colors is likely to result in biased perceived color map. To complement Figure 4 the inset map provides station numbers.

Figure 4. A scatter plot of reflectance derived Forel-Ule Index at each underway station aboard R/V Heincke cruise HE302 between 21 April and 14 May 2009. Using a running average of 11 (red line) we show estimated changes of sea color. The bluing of seawater can be observed, e.g., as the derived FUI from the German Bight towards the North Sea decreases. Inset is a map with the underway station number.

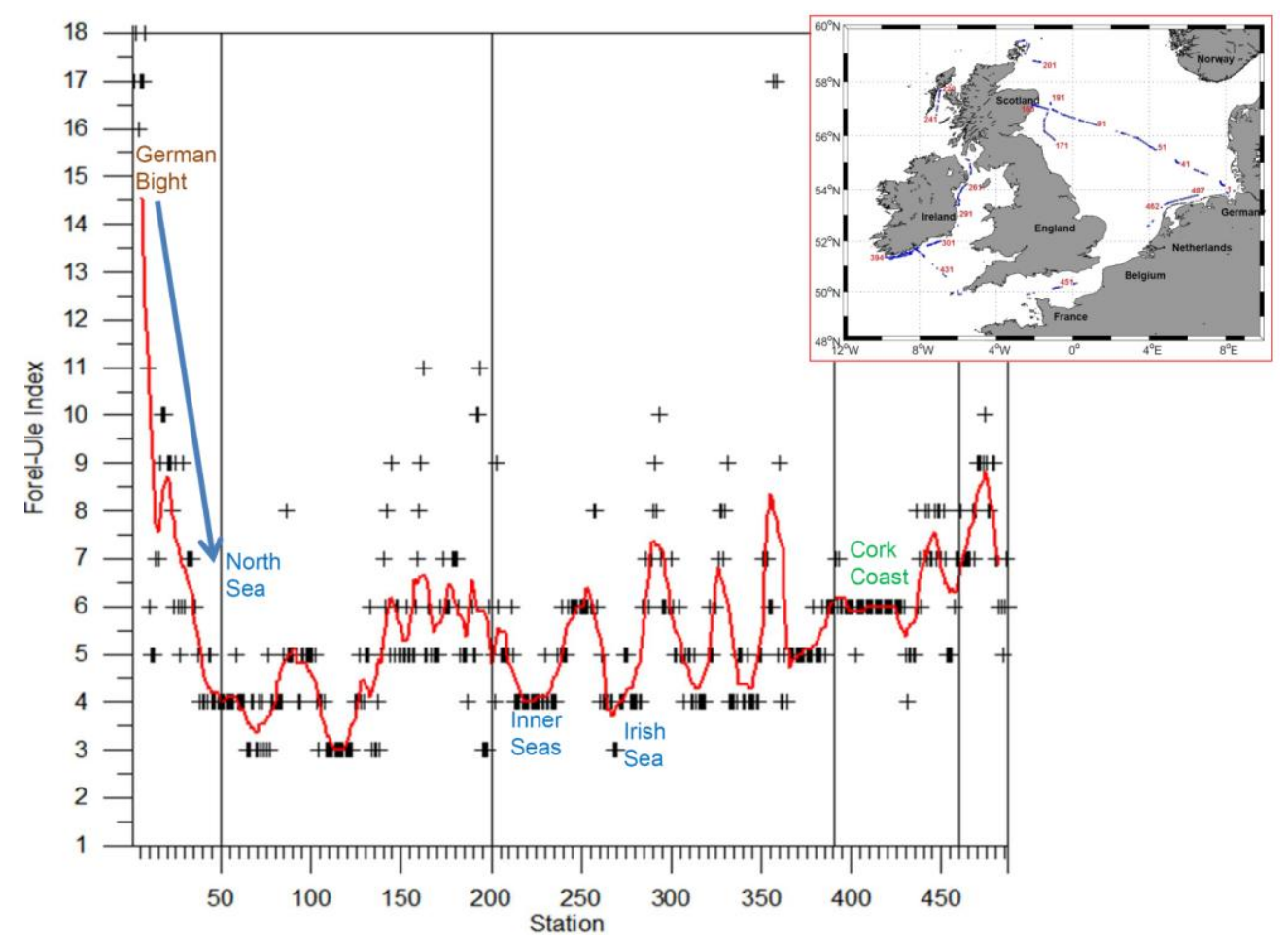




\subsubsection{Using Station Hyperspectral Radiometric Information}

All stations with corresponding in situ sampling had the observed matching spectra transformed into perceived FUI colors are shown in Figure 5. It can be seen that moving away from the highly turbid German Bight (FUI = 17) towards the central North Sea $(F U I=4)$ there is a bluing phenomenon of seawater. Approaching the coast of Scotland (FUI =9) greening effect is visible which suggests a transition from oligotrophic into mesotrophic waters. The mesotrophic waters derive nutrients and particulate material from the Firth of Forth. Moving further north the bluing effect $(\mathrm{FUI}=4)$ took place due to the influence of North Atlantic inflow. This inflow contributes also the color of the Inner Seas. The stations off Ireland were noted to have mostly a light blue color (FUI =6), which is likely to be a result of mixing of oligotrophic Atlantic water with mesotrophic Celtic Sea water.

Figure 5. Map showing color of seawater from sampled stations during the field campaign during R/V Heincke cruise HE302 between 21 April and 14 May 2009. The Forel-Ule information was computed using the derived $R_{R S}$. The numbers represent the Forel-Ule Index matching the color on the scale.

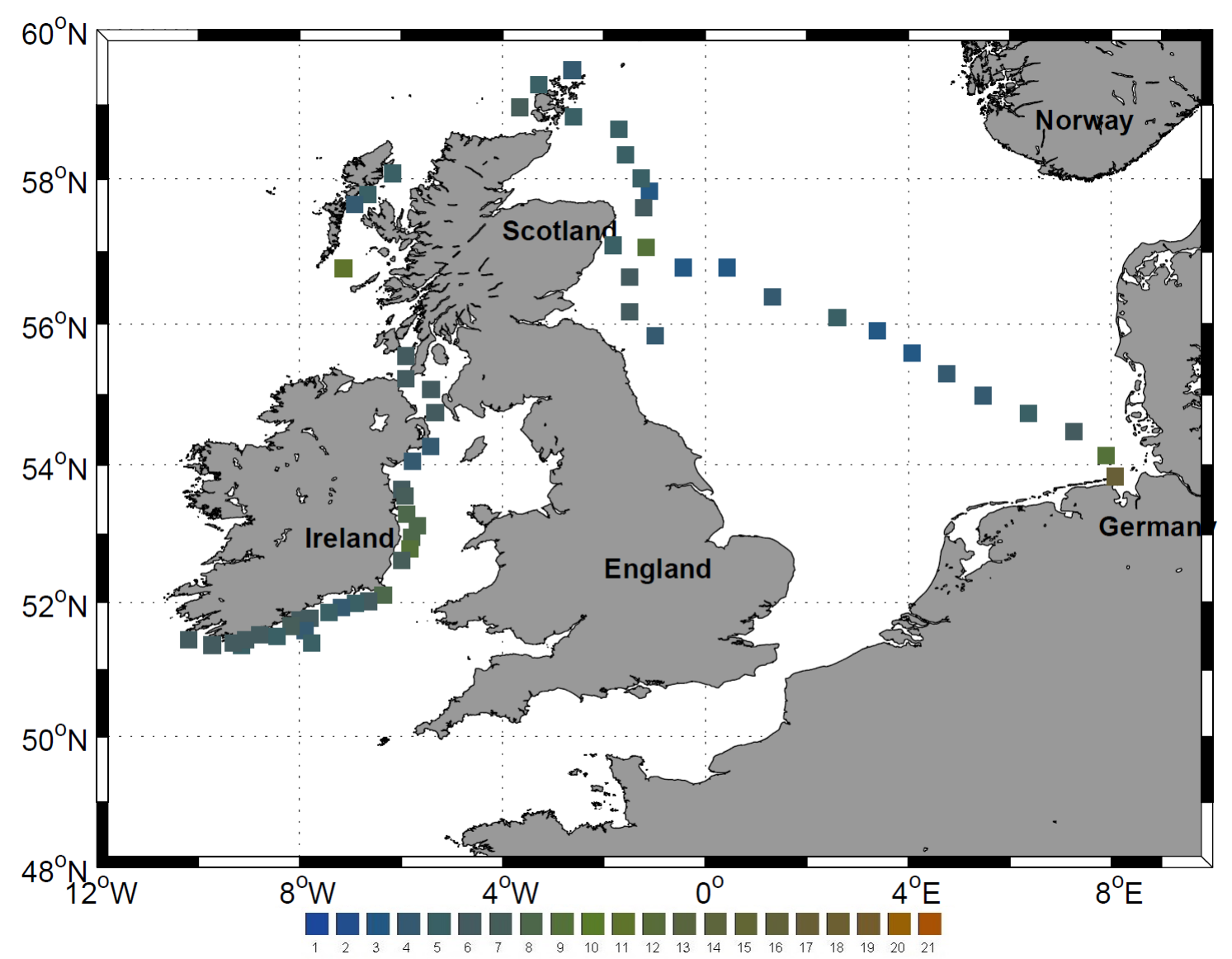

The use of the FUI is gaining interest and has many advantages. Some of the benefits are; FUI is now a standard output of Hydrolight (Sequoia Scientific Inc., Seattle, WA, USA), has a long record which is key in assessing temporal perceived color of seawater changes [53], and is a key parameter in a European Union funded Citizens' Observatory for Coast and Ocean Optical Monitoring (CITCLOPS) project. 
To illustrate its benefit and to show how it complements the classic water body classification approach of Case 1 or Case 2 we apply a band ratio algorithm to classify seawater into Case 1 or Case 2 categories [24]. According to the algorithm Case 2 spectra are expected to have band ratio $443 / 555<443 / 510<490 / 555<490 / 510<1$ [54]. The respective in situ $R_{R S}$ spectra from the 60 sampled stations are shown in Figure 6. These spectra have peaks at $\sim 500, \sim 580$ and $670 \mathrm{~nm}$. Morel and Prier [24] approach is a qualitative water body classification, whereby "blue waters" were assumed to be Case 1 and "various green waters" as Case 2. It is still a key tool in ocean color and is now complemented by FUI. FUI has the advantage of a wide classification ranging 1 (indigo-blue, oligotrophic) to 21 (cola brown, hyper-eutrophic).

Figure 6. Reflectance spectra from the sampled stations.

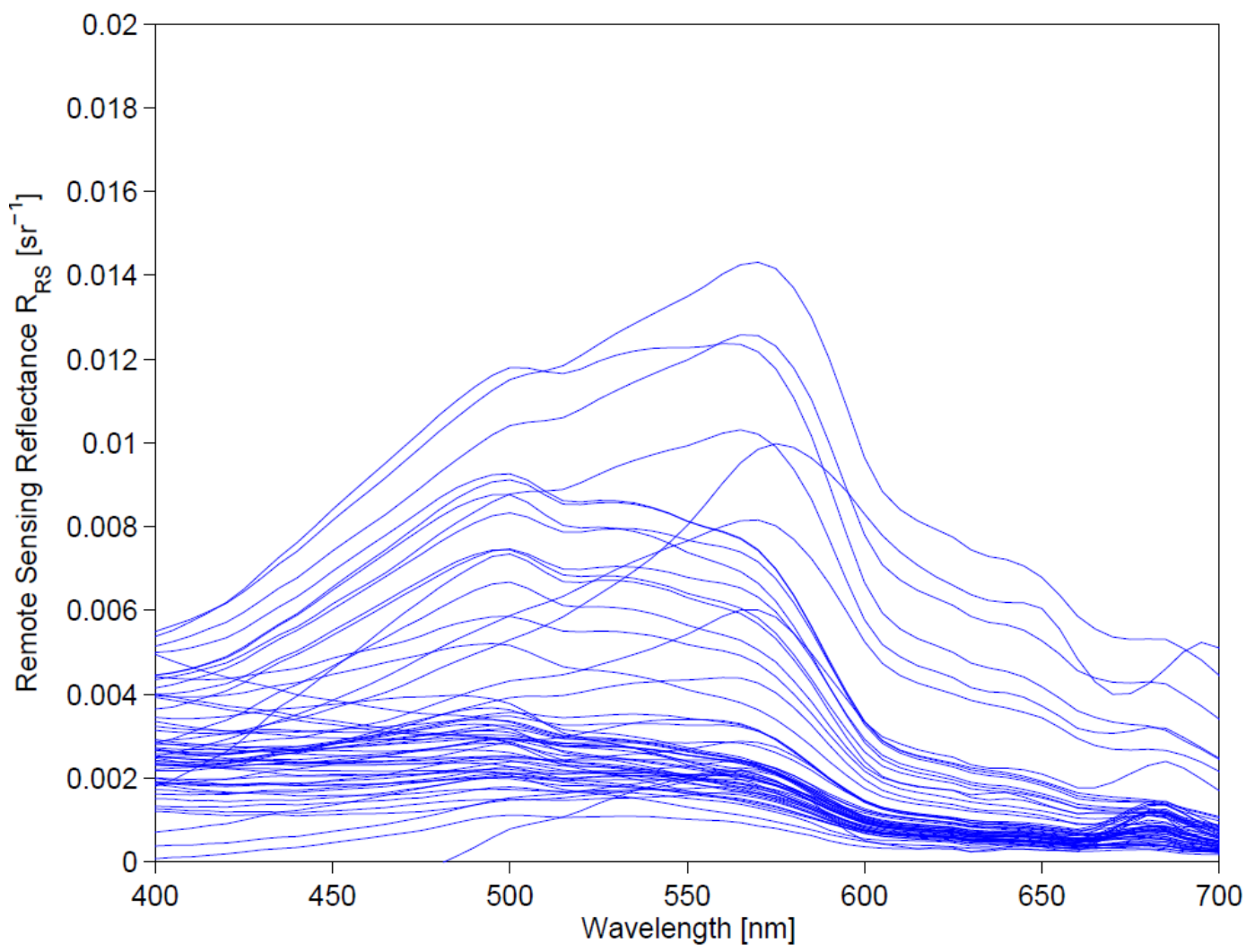

\subsection{Forel-Ule Index (FUI) Colors and Color Producing Agents CPAs}

We explore deriving FUI from CPAs (CDOM, chl- $a$ and iSPM). Here, it is important to consider that chl- $a$ is only one pigment of phytoplankton and generally taken as an indicator of phytoplankton biomass. Other pigments also influence ocean color, therefore the relationship between chl- $a$ and FUI is prone to be influence by these other pigments not measured in this study. The statistics and algorithms are presented in Table 4. The mean UPDs are generally low < 30\%. This can be improved in further investigations with more measurements. It is also possible that the significance and regression coefficients $R$ in our models are influenced by the number of measurements. It will be challenging to decompose the FUI into the respective CPAs although $R_{R S}$ can be used instead to estimate through inversion or bio-optical algorithms. 
Table 4. Multiple linear regression linking reflectance derived Forel-Ule Index (FUI) to colored dissolved organic matter (CDOM), chlorophyll- $a$ (chl- $-a)$, and inorganic fraction of suspended particulate material (iSPM). The statistic are number of available matching points $(N)$, regression coefficient $(R)$ mean unbiased percent difference $(U P D)$ and $F$-statistic ( $p$-value).

\begin{tabular}{cccccc}
\hline Region & $\boldsymbol{F U I}$ & $\boldsymbol{N}$ & $\boldsymbol{R}$ & $\boldsymbol{U P D}$ & $\boldsymbol{p}$-value \\
\hline German Bight & $2.82+5.97 \times \mathrm{CDOM}-0.1 \times \mathrm{chl}-a+0.01 \times \mathrm{iSPM}$ & 7 & 0.83 & $15 \pm 10$ & 0.11 \\
North Sea & $6.28-6.28 \times \mathrm{CDOM}-0.13 \times \mathrm{chl}-a+0.02 \times \mathrm{iSPM}$ & 12 & 0.54 & $27 \pm 28$ & 0.17 \\
Inner Seas & $15.36-26.63 \times \mathrm{CDOM}+0.09 \times \mathrm{chl}-a-0.05 \times \mathrm{iSPM}$ & 8 & 0.66 & $19 \pm 7$ & 0.19 \\
Irish Sea & $6.08-5.16 \times \mathrm{CDOM}-0.59 \times \mathrm{chl}-a+0.20 \times \mathrm{iSPM}$ & 8 & 0.76 & $11 \pm 9$ & 0.10 \\
Celtic Sea & $12.16+1.43 \times \mathrm{CDOM}-1.18 \times \mathrm{chl}-a-0.25 \times \mathrm{iSPM}$ & 12 & 0.39 & $18 \pm 16$ & 0.29 \\
All Seas & $4.09+2.98 \times \mathrm{CDOM}-0.09 \times \mathrm{chl}-a+0.07 \times \mathrm{iSPM}$ & 47 & 0.24 & $22 \pm 14$ & 0.01 \\
\hline
\end{tabular}

A qualitative model is proposed in Figure 7 explaining the processes and dynamics when moving to the open sea from the coast shelf sea and backwards from the open sea to the coast shelf sea.

Figure 7. A conceptual illustration of how perceived color of seawater represented by Forel-Ule Index (FUI) and bio-optical seawater parameters, Secchi-disk depth (SDD), salinity (S), as well as colored dissolved organic material (CDOM) are related.

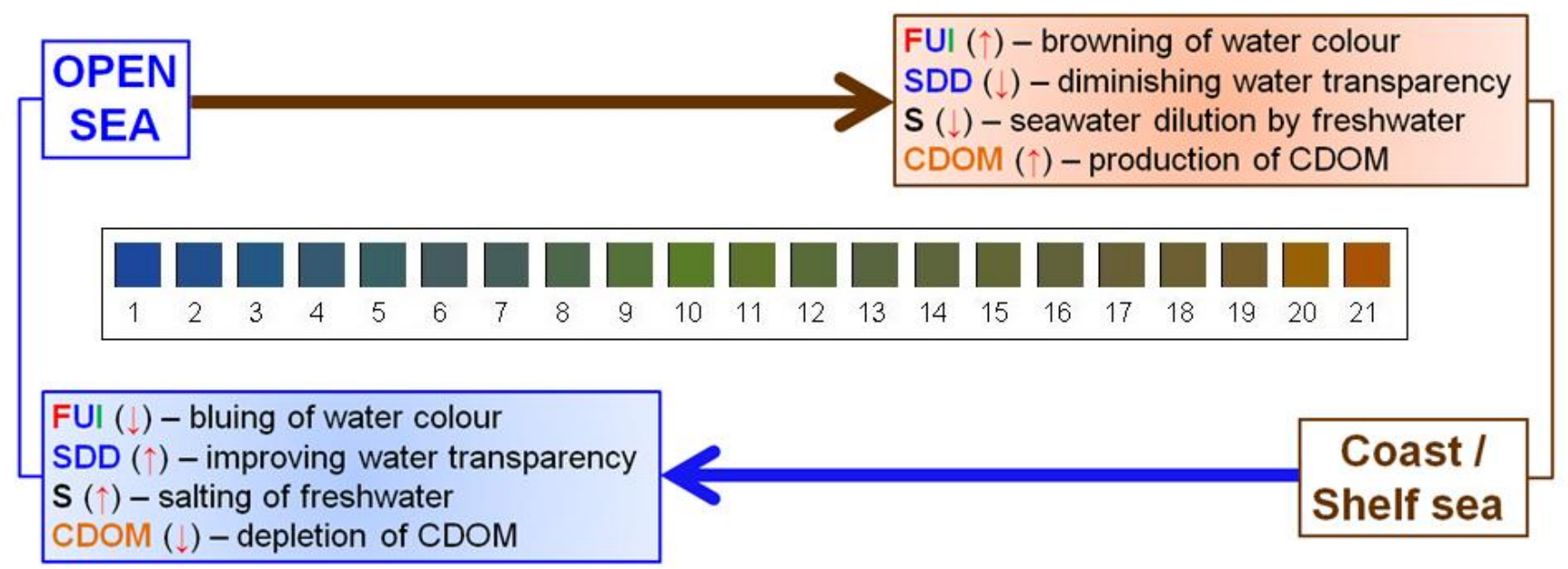

\subsection{Absorption Budgets}

An absorption budget is useful to understand how each CPA contributes to the bulk light absorption. Despite lack of in situ IOP measurements in this study we approximate the absorption coefficient of CPAs from mass-specific absorption of the respective CPA in literature. To compute this bulk absorption coefficient $\mathrm{a}_{\text {total }}(\lambda)[25]$ we use Equation (6),

$$
\mathrm{a}_{\text {total }}(\lambda)=\mathrm{a}_{\text {water }}(\lambda)+\left(\mathrm{a}^{*}{ }_{C D O M}(\lambda) \times C_{C D O M}\right)+\left(\mathrm{a}^{*}{ }_{\text {chl-a }}(\lambda) \times C_{\text {chl-a }}\right)+\left(\mathrm{a}^{*}{ }_{i S P M}(\lambda) \times C_{i S P M}\right)
$$

where $\mathrm{a}_{\text {water }}$ is the absorption coefficient of water [55], $C$ is the mean concentration of each respective CPA (summarized in Appendix Table A1) and $a^{*}$ is the mean concentration-specific absorption coefficient, $\mathrm{a}^{*}{ }_{\mathrm{CDOM}}=e^{(-\mathrm{S}(\lambda-375))}$ derived in Equation (3), $\mathrm{a}^{*}{ }_{c h l-a}=$ Table 4 of [56], $\mathrm{a}^{*}{ }_{i S P M}$ is based on [57]. 
Figure 8 shows general absorption budgets for the different shelf seas. It is the percentage contribution of each component normalized to the total absorption coefficient at each wavelength.

As shown in Figure 8, iSPM is strongly absorbing below $\sim 660 \mathrm{~nm}$ with exception of the German Bight. It can be a result of water condition changes driving a large volume mixing of CPAs. This high concentration of CPAs would likely introduce a high variability in light absorption by the individual CPAs. Additionally, the German Bight is shallow and highly influenced by rivers compared to the other regions investigated here, hence, the distinct absorption variability. Water strongly absorbed in the near infra-red. iSPM absorption was decreasing with wavelength and around $670 \mathrm{~nm}$ the chl- $a$ absorption peak was observed. It is unclear why iSPM (over) dominates absorption in the other water bodies. One assumption is that $\mathrm{a}^{*}$ for iSPM needs to be adjusted along with that of chl- $a$ and CDOM to those of the local conditions.

Figure 8. Average absorption coefficient budget for the Northwest European Shelf Seas. The spectral average absorption of CDOM (red), chl- $a$ (green), iSPM (black) and water (blue) is presented in percentages for each sea.
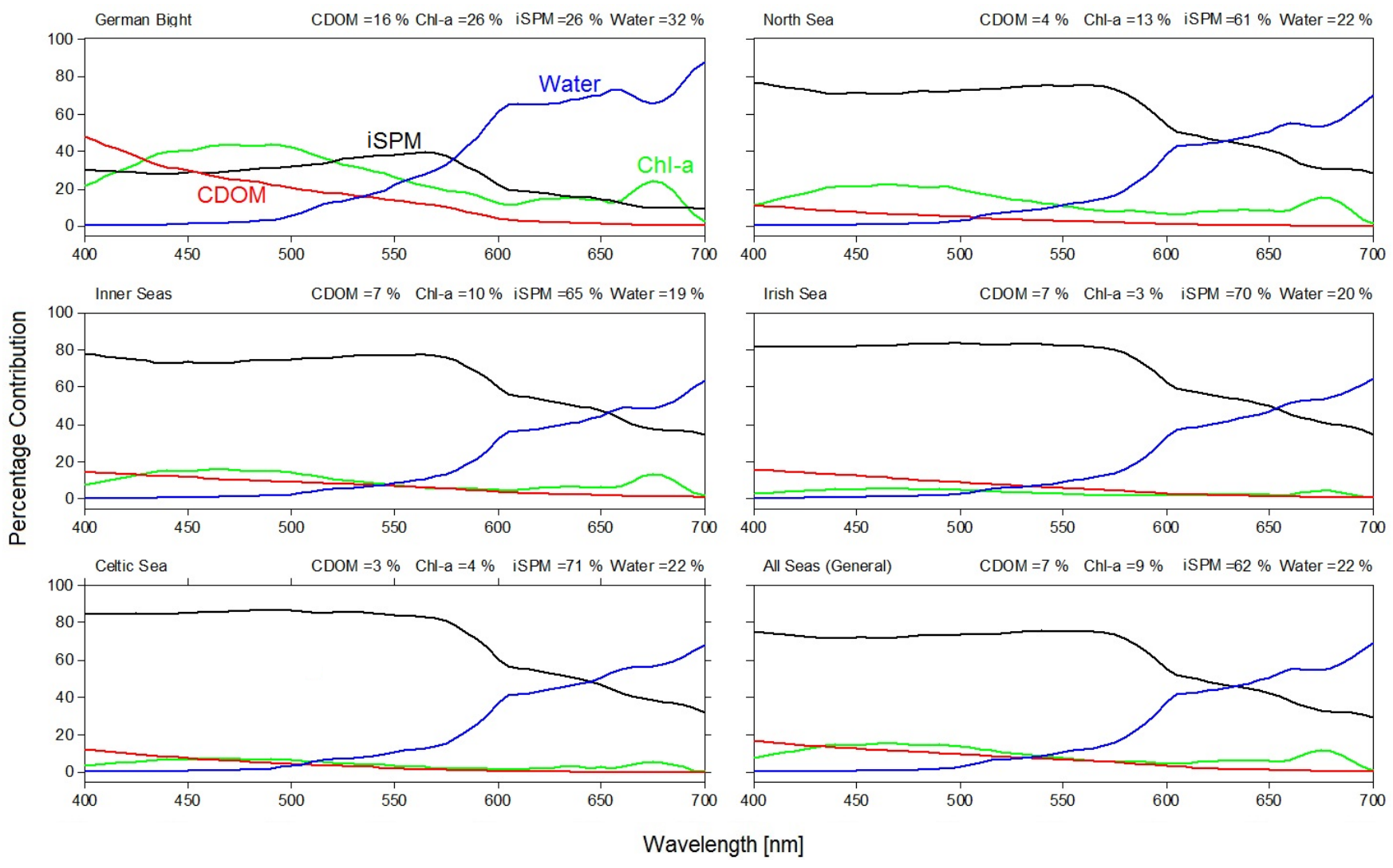

The average absorption of light over the whole spectrum range (400-700) nm as shown in Figure 8 confirm the competition for light between chl- $a$ and iSPM. Our investigations of the north-western European shelf seas suggest that during this time in general iSPM was strongly absorbing light $\sim 70 \%$, followed by water $\sim 18 \%$, chl $-a \sim 7 \%$, and CDOM $\sim 5 \%$. We also present general scattering coefficients of iSPM in different waters (Appendix Figure A8). The mass specific scattering coefficient of iSPM was the mean of the calcareous sand, red clay, yellow clay, and brown earth in Hydrolight (Sequoia Scientific Inc., Seattle, WA, USA). These estimates are relatively within the range of other 
studies [42,57]. We make the assumption here that the water bodies investigated have similar iSPM so as to get a general picture. It is obvious this assumption will only provide an overview. Since we do not have in situ observations it might not be a true representation of in situ conditions, which will vary with time and accuracy of instrument used.

\section{Conclusions}

We examined the extent of correlations among environmental parameters, in northwest European shelf seas. Least square linear regressions were applied and statistical significance $F$-statistic $(p \leq 0.05)$ was observed between CDOM vs. salinity and SDD vs. FUI. The bio-optical models established in this work had low mean unbiased percent differences and absolute percent difference less than 35\%. Other interesting findings were the statistically significant correlations of (i) CDOM and temperature in the North Sea $(\mathrm{R}=0.47)$ and Inner seas $(\mathrm{R}=0.79)$; (ii) FUI and salinity in the German Bight $(\mathrm{R}=0.91)$ and all seas $(\mathrm{R}=0.41)$; (iii) FUI and temperature in the Germany Bight $(\mathrm{R}=0.87)$, Inner Seas ( $R=0.66)$, Celtic Sea $(R=0.28)$ and all seas $(R=0.16)$. These findings have to be studied extensively in the future.

The usefulness of the FUI scale in qualitatively and semi-qualitative (using the indices) for mapping water bodies and monitoring temporal and spatial changes is presented. This study contributes to knowledge gain in the framework of determining quality of marine environments. The presented possible application of mapping water bodies (Figures 4 and 5) are promising indicators for the use of FUI as a qualitative measure of water quality. There is a huge potential to link the new ocean color derived Forel-Ule observations to historical datasets, we use multiple regression to show that using CDOM, chl- $a$, and iSPM the FUI can be determined.

Furthermore, a model (Figure 7) to explain how environmental parameters change nearshore and offshore is proposed. Nearshore it is expected there is browning in the color of water. Low SDD or limited water transparency due to increased suspended particulate material, and enhanced CDOM, and dilution of seawater by freshwater or less saline water from river outlets. These processes are reversed offshore, e.g., salting of freshwater, bluing in the color of water, improved water transparency, and depleted CDOM. Average absorption coefficient budgets showed variability especially in the German Bight. The absorption budget suggests that during the field campaign iSPM was the primary light absorber over a wide spectral range (400-700) nm with CDOM and chl-a being equally low in relevance. The budget was based on assumptions that literature mass specific absorption coefficients are suitable in the different water bodies. The assumption only allows us to obtain a general overview, but in situ observations of absorption and scattering properties are crucial to understand the respective optical characteristics of a water body.

\section{Acknowledgments}

The authors extend their gratitude to the captain and crew of R/V Heincke, R. Henkel, B. Saworski, as well as working groups Zielinski and Cembella for their support during the field campaign. We thank Jan Schulz for discussions on data analysis and the three anonymous reviewers for their invaluable feedback. Support from the European Regional Development Fund (ERDF) funding the Institute of Marine Resources (IMARE) $\mathrm{GmbH}$, Bremerhaven, University of Applied Science 
Bremerhaven and Coastal Observation System for Northern and Arctic Seas (COSYNA) is gratefully acknowledged.

\section{Author Contributions}

Shungudzemwoyo P. Garaba wrote the paper and performed the data analysis. Daniela Voß was responsible for data collection and laboratory analysis on in situ samples and radiometric quantities. Oliver Zielinski was chief scientist of the field campaign, provided the laboratory equipment and radiometers as well as proof reading of manuscript.

\section{Conflicts of Interest}

The authors declare no conflict of interest.

\section{References}

1. Pegau, W.S.; Gray, D.; Zaneveld, J.R.V. Absorption and attenuation of visible and near-infrared light in water: Dependence on temperature and salinity. Appl. Opt. 1997, 36, 6035-6046.

2. Kowalczuk, P.; Ston-Egiert, J.; Cooper, W.J.; Whitehead, R.F.; Durako, M.J. Characterization of Chromophoric Dissolved Organic Matter (CDOM) in the Baltic Sea by excitation emission matrix fluorescence spectroscopy. Mar. Chem. 2005, 96, 273-292.

3. Villagarcía, M.G.; Llinás, O.; Reuter, R.; Rueda, M.J.; Zielinski, O.; Godoy, J. Distribution of gelbstoff fluorescence in the Northern Canary Box. Deep Sea Res. 2002, 49, 3497-3511.

4. Nelson, N.B.; Siegel, D.A. The global distribution and dynamics of chromophoric dissolved organic matter. Ann. Rev. Mar. Sci. 2013, 5, 447-476.

5. Bricaud, A.; Morel, A.; Prieur, L. Absorption by dissolved organic matter of the sea (yellow substance) in the UV and visible domains. Limnol. Oceanogr. 1981, 26, 43-53.

6. Tehrani, N.; D'sa, E.J.; Osburn, C.; Bianchi, T.S.; Schaeffer, B.A. Chromophoric dissolved organic matter and dissolved organic carbon from Sea-Viewing Wide Field-of-View Sensor (SeaWiFS), Moderate Resolution Imaging Spectroradiometer (MODIS) and MERIS Sensors: Case study for the northern Gulf of Mexico. Remote Sens. 2013, 5, 1439-1464.

7. Jerlov, N.G. Influence of suspended and dissolved matter on the transparency of sea water. Tellus 1953, 5, 59-65.

8. Bowers, D.G.; Brett, H.L. The relationship between CDOM and salinity in estuaries: An analytical and graphical solution. J. Mar. Syst. 2008, 73, 1-7.

9. Bowers, D.G.; Evans, D.; Thomas, D.N.; Ellis, K.; Williams, P.J.1.B. Interpreting the colour of an estuary. Est. Coast. Shelf Sci. 2004, 59, 13-20.

10. Zhu, W.; Yu, Q.; Tian, Y.Q.; Becker, B.L.; Zheng, T.; Carrick, H.J. An assessment of remote sensing algorithms for colored dissolved organic matter in complex freshwater environments. Remote Sens. Environ. 2014, 140, 766-778.

11. Boyce, D.G.; Lewis, M.R.; Worm, B. Global phytoplankton decline over the past century. Nature 2010, 466, 591-596. 
12. Kirk, J.T.O. Light and Photosynthesis in Aquatic Ecosystems, 3rd ed.; Cambridge University Press: Cambridge, United Kingdom, 2011; pp. 662.

13. Gitelson, A.A.; Gurlin, D.; Moses, W.J.; Barrow, T. A bio-optical algorithm for the remote estimation of the chlorophyll-a concentration in case 2 waters. Environ. Res. Lett. 2009, 4, doi:10.1088/1748-9326/4/4/045003.

14. Blondeau-Patissier, D.; Tilstone, G.H.; Martinez-Vicente, V.; Moore, G.F. Comparison of bio-physical marine products from SeaWiFS, MODIS and a bio-optical model with in situ measurements from Northern European waters. J. Opt. A: Pure Appl. Opt. 2004, 6, 875-889.

15. Dierssen, H.M.; Kudela, R.M.; Ryan, J.P.; Zimmerman, R.C. Red and black tides: Quantitative analysis of water-leaving radiance and perceived color for phytoplankton, colored dissolved organic matter, and suspended sediments. Limnol. Oceanogr. 2006, 51, 2646-2659.

16. Watson, J., Zielinski, O. Eds. Subsea Optics and Imaging; Woodhead Publishing Limited (Elsevier imprint): Cambridge, UK, 2013; p. 608.

17. Sundermann, J.; Prandle, D.; Lankester, R.; McCave, I.N. Suspended particulate matter in the North Sea: Field observations and model simulations (and discussion). Phil. Trans. R. Soc. A 1993, 343, 423-430.

18. Sathyendranath, S.; Prieur, L.; Morel, A. A three-component model of ocean colour and its application to remote sensing of phytoplankton pigments in coastal waters. Int. J. Remote Sens. 1989, 10, 1373-1394.

19. Bukata, R.P.; Jerome, J.H.; Kondratyev, K.Y.; Pozdnyakov, D.V. Optical Properties and Remote Sensing of Inland and Coastal Waters; CRC Press: Boca Raton, FL, USA, 1995; pp. 362.

20. Moreno-Madrinan, M.J.; Al-Hamdan, M.Z.; Rickman, D.L.; Muller-Karger, F.E. Using the surface reflectance MODIS terra product to estimate turbidity in Tampa Bay, Florida. Remote Sens. 2010, 2, 2713-2728.

21. Neukermans, G.; Ruddick, K.; Loisel, H.; Roose, P. Optimization and quality control of suspended particulate matter concentration measurement using turbidity measurements. Limnol. Oceanogr.-Meth. 2012, 10, 1011-1023.

22. Moore, G.K. Satellite remote sensing of water turbidity. Hydrol. Sci. J. 1980, 25, 407-421.

23. Vollenweider, R.A.; Kerekes, J. Eutrophication of Waters. Monitoring, Assessment and Control; Environment Directorate for Economic Co-Operation and Development (OECD) Cooperative programme on monitoring of inland waters (Eutrophication control): Paris, France, 1982; p. 154.

24. Morel, A.; Prieur, L. Analysis of variations in ocean color. Limnol. Oceanogr. 1977, 22, 709-722.

25. Prieur, L.; Sathyendranath, S. An optical classification of coastal and oceanic waters based on the specific spectral absorption curves of phytoplankton pigments, dissolved organic matter, and other particulate materials. Limnol. Oceanogr. 1981, 26, 671-689.

26. Wernand, M.R. Poseidons Paintbox: Historical Archives of Ocean Colour in Global-Change Perspective. Ph.D. Thesis. Utrecht University, Utrecht, The Netherlands, 2011.

27. Hoguane, A.M.; Green, C.L.; Bowers, D.G.; Nordez, S. A note on using a digital camera to measure suspended sediment load in Maputo Bay, Mozambique. Remote Sens. Lett. 2012, 3 , 259-266.

28. Akkaynak, D.; Hanlon, R.T. Capturing accurate colors underwater with consumer digital cameras COTS digital cameras combined with spectrometers aid color capture. Sea Technol. 2012, 53, 10. 
29. Moore, C.; Barnard, A.; Fietzek, P.; Lewis, M.R.; Sosik, H.M.; White, S.; Zielinski, O. Optical tools for ocean monitoring and research. Ocean Sci. 2009, 5, 661-684.

30. Souza, A.J.; Holt, J.T.; Proctor, R. Modelling SPM on the NW European shelf seas. Geol. Soc. Spec. Publ. 2007, 274, 147-158.

31. Barale, V. The European Marginal and Enclosed Seas: An Overview In Remote Sensing of the European Seas; Barale, V., Gade, M., Eds.; Springer: Berlin, Germany, 2008; pp. 3-22.

32. Hubert, L.; Lubac, B.; Dessailly, D.; Duforet-Gaurier, L.; Vantrepotte, V. Effect of inherent optical properties variability on the chlorophyll retrieval from ocean color remote sensing: An in situ approach. Opt. Express 2010, 18, 20949-20959.

33. McKee, D.; Cunningham, A. Identification and characterisation of two optical water types in the Irish Sea from in situ inherent optical properties and seawater constituents. Est. Coast. Shelf Sci. 2006, 68, 305-316.

34. Bundesamt für Seeschifffahrt und Hydrographie. Available online: http://www.bsh.de (accessed on 10 January 2014).

35. International Hydrographic Organization. Available online: http://www.iho.int/srv1/ (accessed on 11 January 2014).

36. Garaba, S.P.; Schulz, J.; Wernand, M.R.; Zielinski, O. Sunglint detection for unmanned and automated platforms. Sensors 2012, 12, 12545-12561.

37. Garaba, S.P.; Zielinski, O. Methods in reducing surface reflected glint for shipborne above-water remote sensing. J. Eur. Opt. Soc. Rap. Public 2013, 8, 13058.

38. Garaba, S.P.; Henkel, R.; Krock, B.; Voß, D.; Zielinski, O. Radiance, irradiance, and remote sensing reflectance during the North Sea Coast Harmful Algal Bloom (NORCOHAB II) RV HEINCKE cruise HE302. PANGAEA 2011, doi:10.1594/PANGAEA.759690.

39. Arar, E.J. Method 446.0 In Vitro Determination of Chlorophylls a, b, $c_{1}+c_{2}$ and Pheopigments in Marine and Freshwater Algae by Visible Spectrophotometry. In Methods for the Determination of Chemical Substances in Marine and Estuarine Environmental Matrices; USA Environmental Protection Agency: Washington, DC, USA, 1997; pp. 163-188.

40. Babin, M.; Stramski, D.; Ferrari, G.M.; Claustre, H.; Bricaud, A.; Obolensky, G.; Hoepffner, N. Variations in the light absorption coefficients of phytoplankton, nonalgal particles, and dissolved organic matter in coastal waters around Europe. J. Geophys. Res. 2003, 108, doi:10.1029/2001JC000882.

41. Kowalczuk, P. Seasonal variability of yellow substance absorption in the surface layer of the Baltic Sea. J. Geophys. Res. 1999, 104, 30047-30058.

42. Tilstone, G.H.; Peters, S.W.M.; van der Woerd, H.J.; Eleveld, M.A.; Ruddick, K.; Schönfeld, W.; Krasemann, H.; Martinez-Vicente, V.; Blondeau-Patissier, D.; Röttgers, R.; et al.. Variability in specific-absorption properties and their use in a semi-analytical ocean colour algorithm for MERIS in North Sea and Western English Channel Coastal Waters. Remote Sens. Environ. 2012, 118, 320-338.

43. Siegel, D.A.; Behrenfeld, M.J.; Maritorena, S.; McClain, C.R.; Antoine, D.; Bailey, S.W.; Bontempi, P.S.; Boss, E.S.; Dierssen, H.M.; Doney, S.C.; et al. Regional to global assessments of phytoplankton dynamics from the SeaWiFS mission. Remote Sens. Environ. 2013, 135, 77-91. 
44. Garaba, S.P.; Zielinski, O. Comparison of remote sensing reflectance from above-water and in-water measurements west of Greenland, Labrador Sea, Denmark Strait, and west of Iceland. Opt. Express 2013, 21, 15938-15950.

45. Zielinski, O.; Krock, B.; Henkel, R.; Voß, D. Physical oceanography during the North Sea Coast Harmful Algal Bloom (NORCOHAB II) RV HEINCKE cruise HE302. PANGAEA 2010, doi:10.1594/PANGAEA.754230.

46. Zielinski, O.; Krock, B.; Henkel, R.; Voß, D. Transparency measurements with Secchi disc during HEINCKE cruise HE302. PANGAEA 2010, doi:10.1594/PANGAEA.754259.

47. Radach, G.; Pätsch, J. Climatological annual cycles of nutrients and chlorophyll in the North Sea. J. Sea Res. 1997, 38, 231-248.

48. Longhurst, A.R. Ecological Geography of the Sea, 2nd ed.; Academic Press (Elsevier Imprint): Burlington, VT, USA, 2007; p. 560.

49. Lübben, A.; Dellwig, O.; Koch, S.; Beck, M.; Badewien, T.; Fischer, S.; Reuter, R. Distributions and characteristics of dissolved organic matter in temperate coastal waters (Southern North Sea). Ocean Dyn. 2009, 59, 263-275.

50. Cefas. EMECO European Marine Ecosystem Observatory. Available online: http://www.emecodata.net/ (accessed on 10 January 2014).

51. Del Vecchio, R.; Blough, N.V. Spatial and seasonal distribution of chromophoric dissolved organic matter and dissolved organic carbon in the Middle Atlantic Bight. Mar. Chem. 2004, 89, 169-187.

52. Werdell, P.J.; Franz, B.A.; Bailey, S.W.; Feldman, G.C.; Boss, E.; Brando, V.E.; Dowell, M.; Hirata, T.; Lavender, S.J.; Lee, Z.; et al. Generalized ocean color inversion model for retrieving marine inherent optical properties. Appl. Opt. 2013, 52, 2019-2037.

53. Wernand, M.R.; van der Woerd, H.J.; Gieskes, W.W.C. Trends in ocean colour and chlorophyll concentration from 1889 to 2000, worldwide. PLoS One 2013, 8, e63766.

54. Ouillon, S.; Petrenko, A. Above-water measurements of reflectance and chlorophyll-a algorithms in the Gulf of Lions, NW Mediterranean Sea. Opt. Express 2005, 13, 2531-2548.

55. Pope, R.M.; Fry, E.S. Absorption spectrum (380-700 nm) of pure water. II. Integrating cavity measurements. Appl. Opt. 1997, 36, 8710-8723.

56. Gallegos, C.L.; Correll, D.L.; Pierce, J.W. Modeling spectral diffuse attenuation, absorption, and scattering coefficients in a turbid estuary. Limnol. Oceanogr. 1990, 35, 1486-1502.

57. Bowers, D.G.; Binding, C.E. The optical properties of mineral suspended particles: A review and synthesis. Est. Coast. Shelf Sci. 2006, 67, 219-230. 


\section{Appendix}

Table A1. Summary of measurements used in this study from the northwest European shelf seas. Each parameter is presented as mean \pm standard deviation for $N$ stations observed.

\begin{tabular}{ccccccccc}
\hline Region & CDOM 375 nm $(\mathbf{L} / \mathbf{m})$ & Chl- $\boldsymbol{a}(\boldsymbol{\mu} / \mathbf{L})$ & iSPM $(\mathbf{m g} / \mathbf{L})$ & Forel-Ule Index & Salinity (psu) & $\begin{array}{c}\text { Secchi Disk } \\
\text { Depth }(\mathbf{m})\end{array}$ & Temperature $\left({ }^{\circ} \mathbf{C}\right)$ & Turbidity $(\mathbf{F T U})$ \\
\hline German Bight & $0.63 \pm 0.51$ & $9.09 \pm 5.88$ & $3.62 \pm 4.58$ & $6 \pm 5$ & $33.03 \pm 2.60$ & $8.6 \pm 4.5$ & $8.41 \pm 1.22$ & $0.31 \pm 0.20$ \\
North Sea & $0.22 \pm 0.10$ & $7.33 \pm 11.58$ & $14.00 \pm 12.36$ & $5 \pm 2$ & $34.81 \pm 0.21$ & $7.83 \pm 2.06$ & $8.01 \pm 0.42$ \\
Inner Seas & $0.33 \pm 0.07$ & $6.16 \pm 4.25$ & $18.54 \pm 6.99$ & $6 \pm 2$ & $34.39 \pm 0.54$ & $7.64 \pm 2.40$ & $8.94 \pm 0.57$ & $0.20 \pm 0.19$ \\
Irish Sea & $0.36 \pm 0.04$ & $2.08 \pm 0.95$ & $18.58 \pm 6.95$ & $7 \pm 2$ & $33.98 \pm 0.17$ & $4.46 \pm 1.81$ & $9.58 \pm 0.42$ & $0.68 \pm 0.42$ \\
Celtic Sea & $0.27 \pm 0.12$ & $2.28 \pm 1.14$ & $16.31 \pm 5.34$ & $6 \pm 1$ & $34.89 \pm 0.26$ & $5.95 \pm 0.91$ & $10.07 \pm 0.52$ \\
\hline
\end{tabular}

Figure A1. A plot showing the measured environmental properties; colored dissolved organic matter (CDOM), chlorophyll-a (Chl-a), inorganic fraction of suspended particulate material (iSPM), Forel-Ule Index (FUI), salinity (Sal), Secchi-disk depth (SDD), temperature (Temp), and turbidity (Turb) in the northwest European shelf seas.

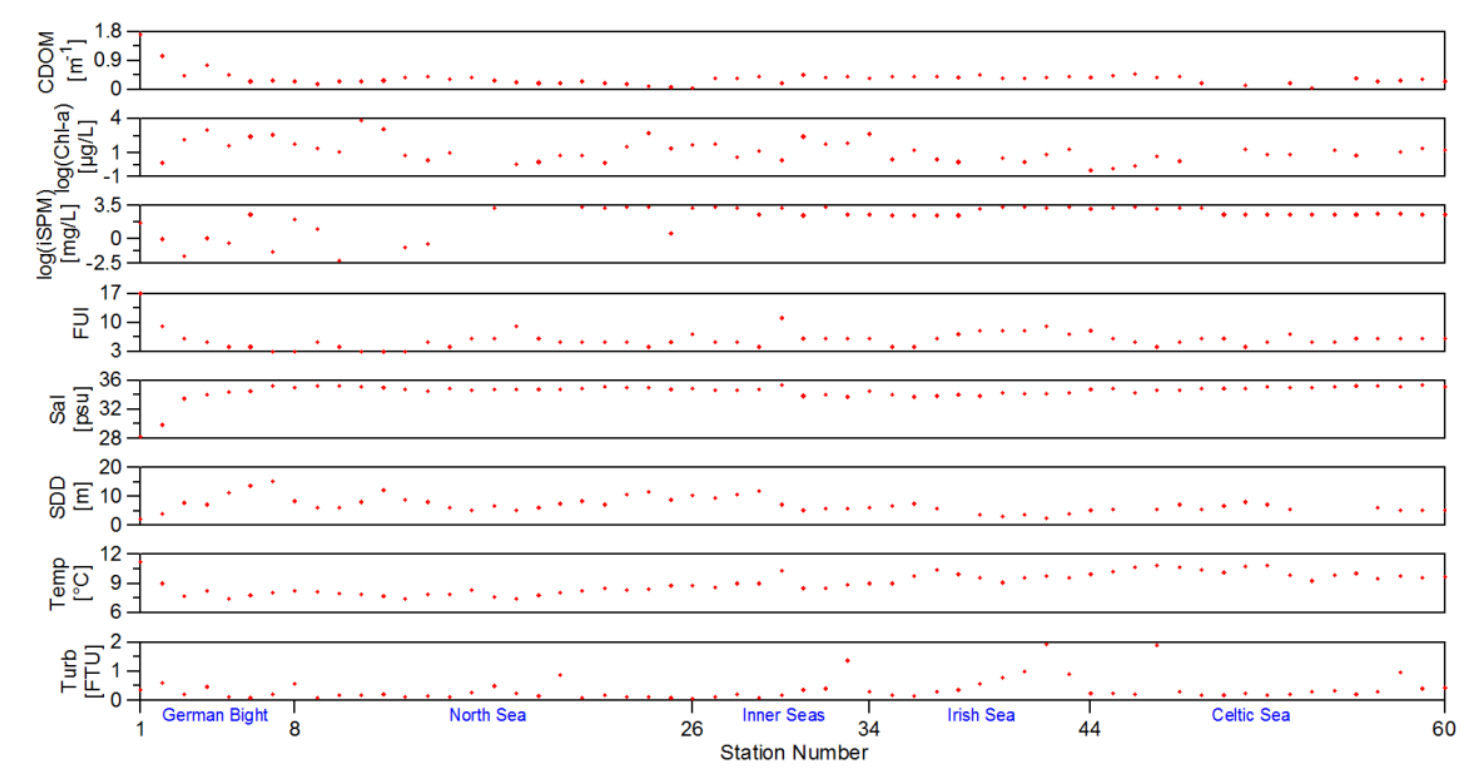


Figure A2. Statistics (correlation coefficient $r$-squared $R, F$-statistic $p$-value $p$, and number of data points $N$ ) for the environmental properties measured in the German Bight.

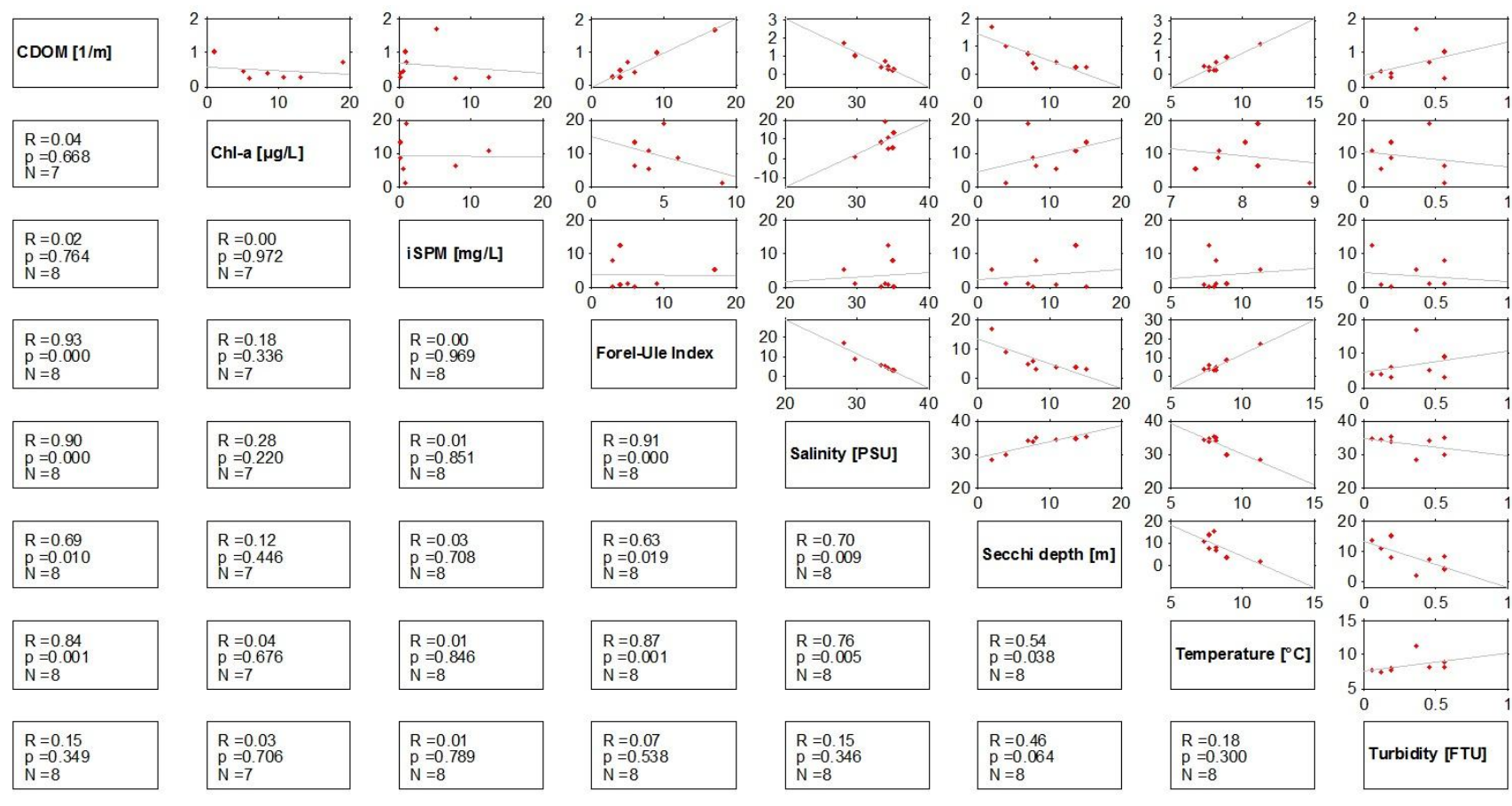

Figure A3. Statistics (correlation coefficient $r$-squared $R, F$-statistic $p$-value $p$, and number of data points $N$ ) for the environmental properties measured in the North Sea.

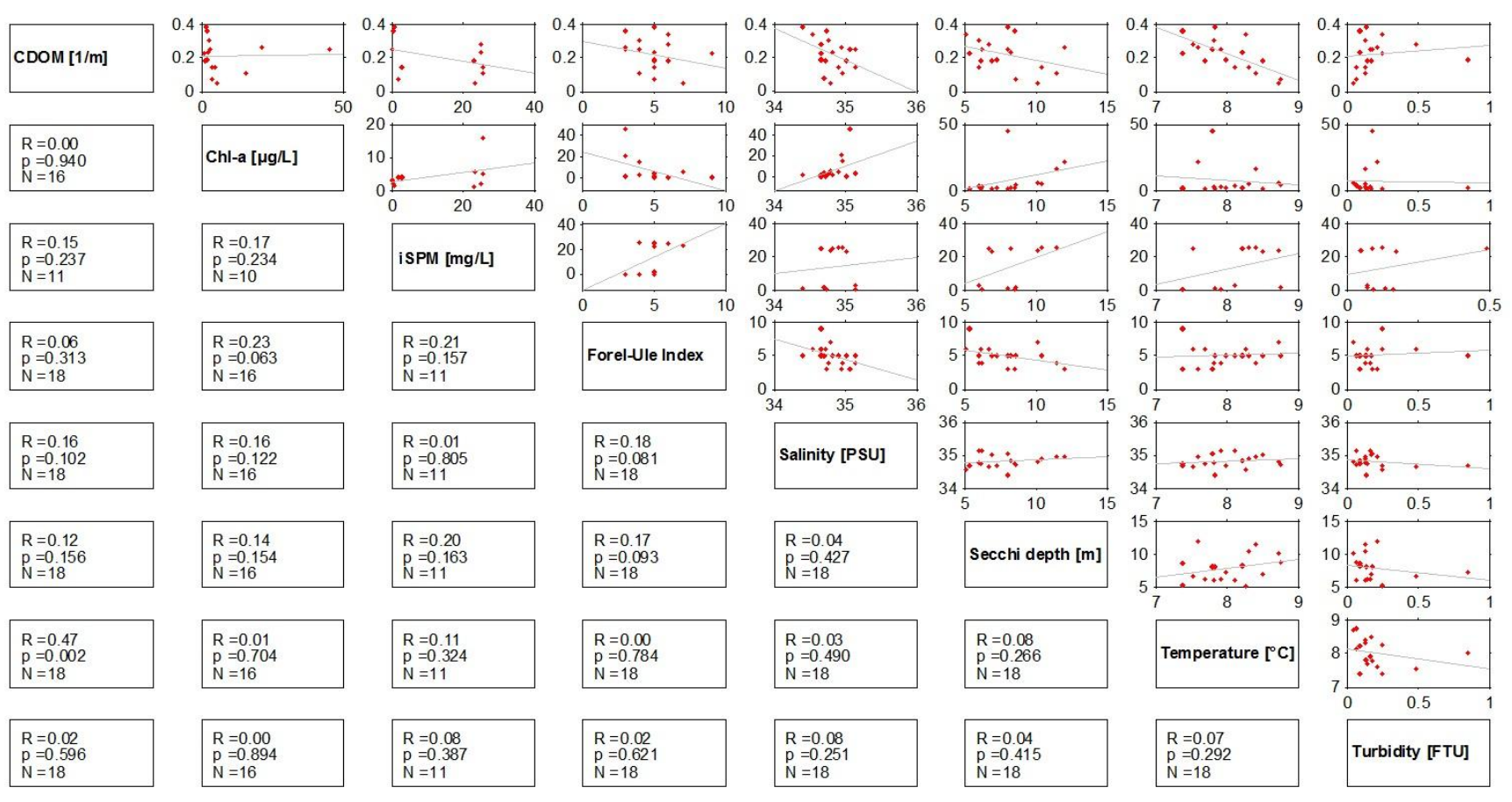


Figure A4. Statistics (correlation coefficient $r$-squared $R, F$-statistic $p$-value $p$, and number of data points $N$ ) for the environmental properties measured in the Inner Seas.

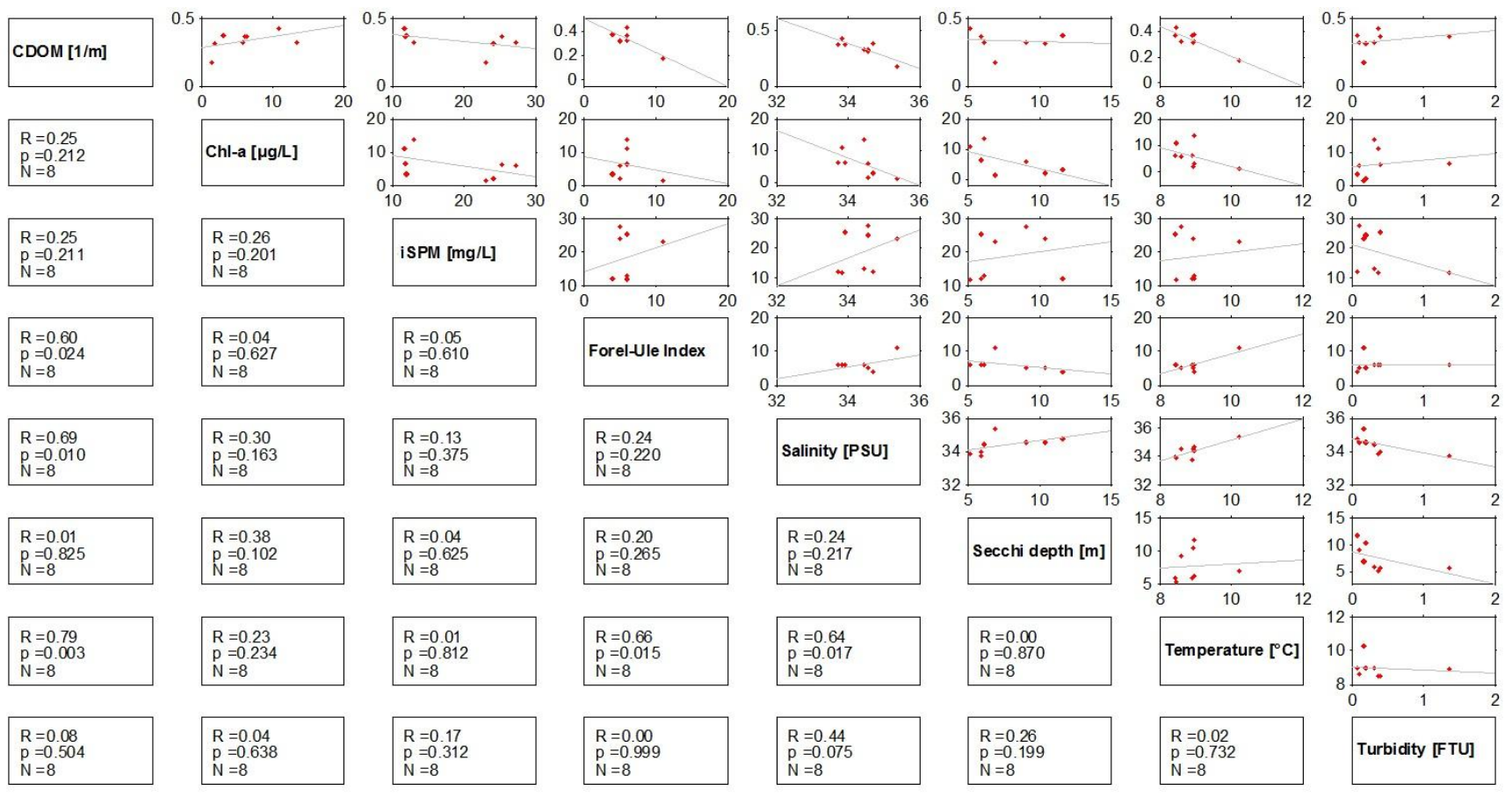

Figure A5. Statistics (correlation coefficient $r$-squared $R, F$-statistic $p$-value $p$, and number of data points $N$ ) for the environmental properties measured in the Irish Sea.

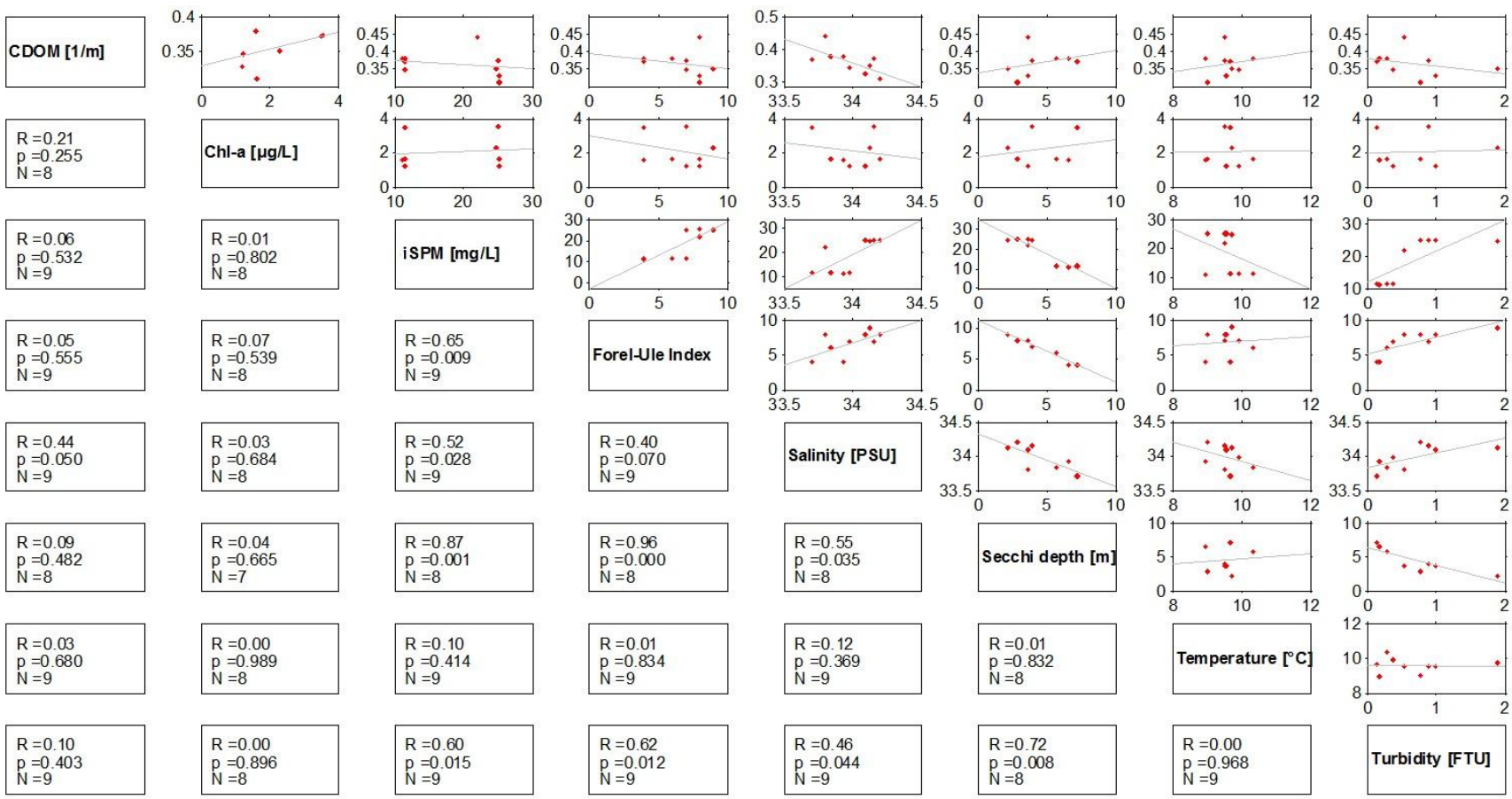


Figure A6. Statistics (correlation coefficient $r$-squared $R, F$-statistic $p$-value $p$, and number of data points $N$ ) for the environmental properties measured in the Celtic Sea.

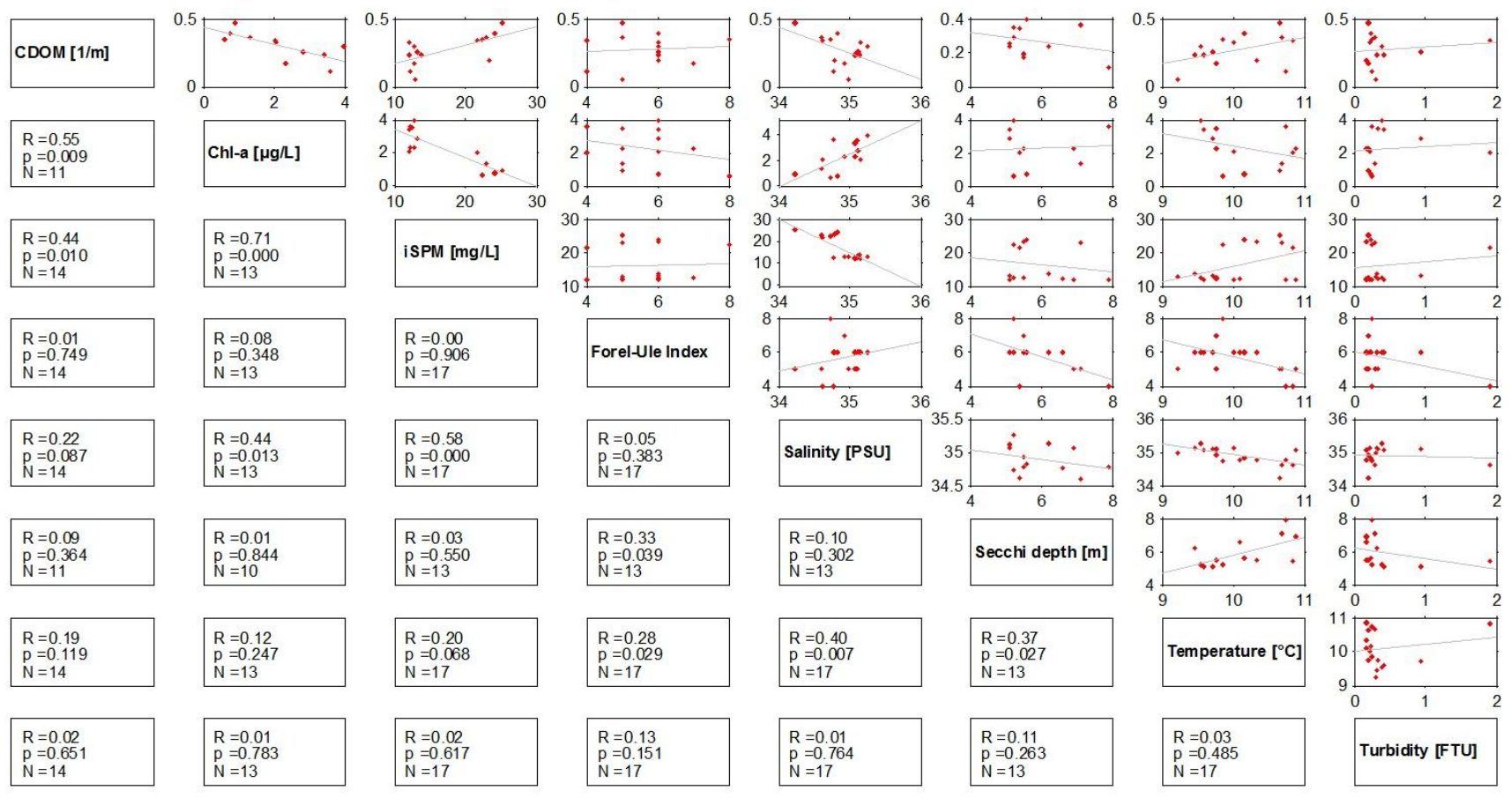

Figure A7. Average absorption coefficients for the northwest European shelf seas.
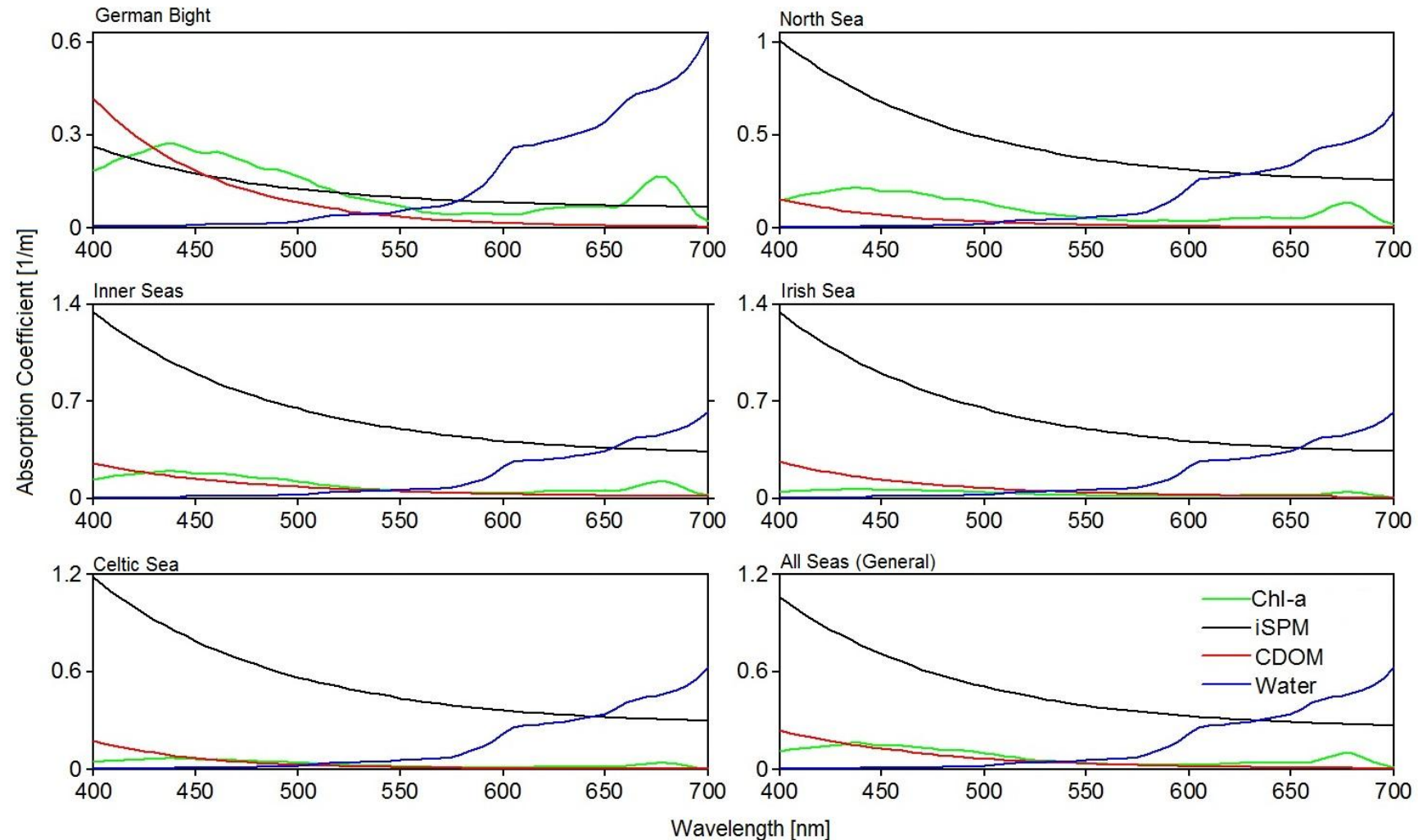
Figure A8. Average scattering coefficients for the northwest European shelf seas. The mass specific scattering coefficient of iSPM was the mean of the calcareous sand, red clay, yellow clay, and brown earth in Hydrolight (Sequoia Scientific Inc., Seattle, WA, USA). Note that the calculated mean scattering coefficients for Inner Seas and Irish Sea have an overlay.

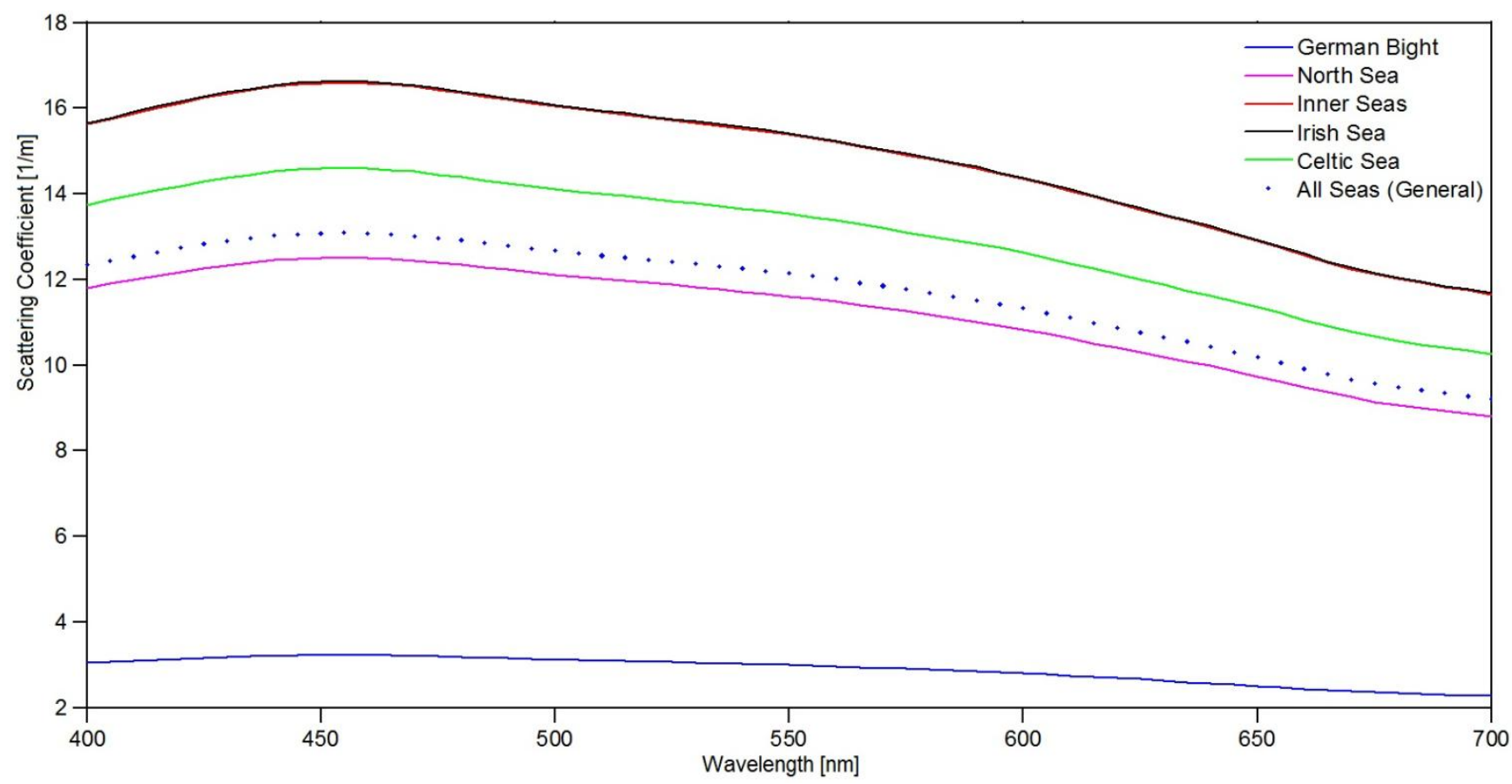

(C) 2014 by the authors; licensee MDPI, Basel, Switzerland. This article is an open access article distributed under the terms and conditions of the Creative Commons Attribution license (http://creativecommons.org/licenses/by/3.0/). 